Byzantion Nea Hellás 28, 2009: 127-164

\title{
LA ROMANIDAD ORIENTAL MODERNA: UN TESTIMONIO SOBRE EL PAPEL RELIGIOSO Y POLÍTICO DE LA ÉLITE CRISTIANA HELENOHABLANTE DE CONSTANTINOPLA EN EL SIGLO XVIII
}

\section{Xavier Agati École des Hautes Études en Sciences Sociales. París Francia}

Resumen: En este ensayo, examino fragmentos escogidos de los Asuntos eclesiásticos y políticos de A. Komninós Ipsilántis, obra escrita en el siglo XVIII en griego arcaizante y antiguo en el Imperio Otomano. Estos fragmentos se refieren a dos dignatarios que representan, de forma particular, la legitimidad bizantina en el Imperio Otomano.

Este trabajo busca situar la cultura romana oriental en las dimensiones de su contexto intrínseco, tal y como era considerada por sus actantes, y no tan sólo por tradiciones exteriores.

Palabras claves : Patriarca de Constantinopla, rûm, fanariota, Athanásios Ipsilántis, Aléxandros Ipsilántis

\section{THE MODERN ORIENTAL ROMANITY A TESTIMONY ABOUT THE RELIGIOUS AND POLITICAL ROLE OF THE CHRISTIAN GREEK-SPEAKING ELITE OF CONTANTINOPLE DURING THE XVIIITH CENTURY.}

Abstract: In this essay, I examine fragments chosen from the Ecclesiastical and Political Affairs by A. Komninós Ipsilántis, a work written in the XVIIIth century in archaizing and ancient greek in the Ottoman Empire. These fragments refer to two dignitaries who represent, in particular way, byzantine legitimacy in the Ottoman Empire.

The essay aims at situating the oriental roman culture within the dimensions of its inner context, as it was considered by its actors at that moment, and not just by foreign traditions.

Key words: Patriarch of Constantinople, rûm, phanariot, Athanásios Ipsilántis, Aléxandros Ipsilántis

Aceptado: 11.08 .08 - Recibido: 7.10 .08

Correspondencia: Xavier Agati (xavier agati@yahoo.fr). Tel: 033476840075. Doctorado en el Centro bizantino y del sudeste europeo y el Centro de Historia otomana, EHESS (Ecole des Hautes Etudes en Sciences Sociales) de Paris - Profesor de Letras Clásicas, Escuela Internacional Europole y Universidad de Grenoble (Francia) 
Xavier. Agati: La romanidad oriental moderna: un testimonio sobre el papel...

$\mathrm{E}$ ste estudio se apoya en la traducción de una parte de la obra monumental titulada Asuntos eclesiásticos y políticos, del dignatario cristiano helenohablante otomano Athanásios Komninós Ipsilántis, escrita en la segunda mitad del siglo XVIII.

No considero aquí sino dos conjuntos de fragmentos de mi traducción de la obra y, apoyándome en ellos, pretendo una reflexión sobre la trascendencia de este testimonio en la confirmación de la idea que tenemos de una continuidad bizantina (y por lo tanto romana) asumida por la Iglesia de Constantinopla y por la élite cristiana helenohablante del Imperio otomano.

Para poder explotar correctamente estos fragmentos, conviene hacer una breve aclaración de ciertos términos relativos al contexto específicamente bizantinootomano de la obra. Una vez llevada a cabo dicha aclaración, presentaré la posición de la Iglesia de Constantinopla y de los súbditos helenohablantes del Imperio otomano en el siglo XVIII, así como elementos de la obra de Ipsilántis. Finalmente, me concentraré en los elementos que aportan los fragmentos escogidos sobre la importancia religiosa y política de hombres de Estado cristianos helenohablantes en el seno del gobierno otomano al final del siglo XVIII.

\section{I- Aclaración de ciertos términos utilizados en este trabajo}

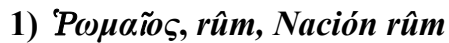

Para designar a todos los cristianos de confesión calcedonia ortodoxa del Imperio otomano y, por lo tanto, de lengua jerárquica de referencia griega, el autor

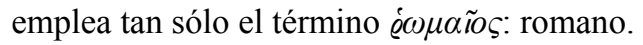

Según sus parámetros, siguiendo toda la tradición bizantina, el Imperio romano persiste sin discontinuidad a través del Imperio bizantino, incluso hasta el final del Imperio otomano. La lógica imperial predomina sobre el origen étnico y sobre la religión de los soberanos.

Esta palabra corresponde concretamente a la palabra turca otomana rûm (روم) que empleo para la traducción. Hoy por hoy los turcos establecen aun la diferencia entre rûm y griego de Grecia.

Sin embargo, los cristianos calcedonios ortodoxos del Imperio otomano tenían como lengua materna y como lengua litúrgica otras lenguas fuera del griego: el rumano, el serbio, el búlgaro, el turco, el árabe, el georgiano, el albanés, etc... No obstante lo que sí puede asegurarse es que la palabra rumca (lengua rûm) llegó a designar únicamente el idioma griego.

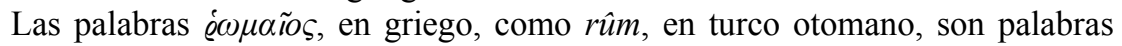
que sólo pueden aprehenderse en un contexto imperial: son palabras que se oponen a «griego» y a «heleno», que están demasiado ligadas a la problemática de la independencia de Grecia.


romana, que corresponde al otomano Millet-i rûm. Este término designa la comunidad 
rûm definida por su confesión en el sistema administrativo otomano. De hecho, los súbditos del Imperio otomano estaban agrupados y administrados según su obediencia religiosa.

En el siglo XVIII los cristianos no calcedonios, es decir, las diferentes iglesias monofisitas (armenia, copta, etiópica, siria occidental) y la Iglesia nestoriana siria oriental dependen, por su parte, del patriarca armenio.

En consecuencia, es interesante ver que en el Imperio otomano la lengua griega es una lengua imperial superviviente hasta el final, también entre los R̂̂m, y hasta entre los no helenohablantes.

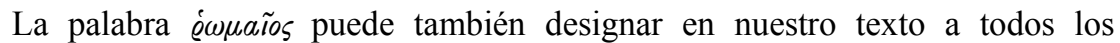
súbditos -incluidos musulmanes y judíos- del Imperio Otomano. Esta denominación es típicamente bizantina, en tanto considera la perennidad romana como más importante que las fracturas de la historia. Por otro lado, esta palabra hace referencia a otra tradición, la tradición persa (especialmente selyúcida): el Imperio Otomano, persohablante y turcohablante, se considera a sí mismo no sólo como heredero del Imperio Bizantino, sino también del Sultanato Selyúcida turco-persa de Anatolia, llamado de Rûm, es decir de los Romanos, del que era originalmente vasallo.

\section{2) Voivoda}

Los voivodas de Valaquia y de Moldavia se designan con diferentes vocablos en el texto: griegos, rumanos o turco otomanos. De hecho, su dignidad es políticamente perceptible en las tres culturas.

Moldavia y Valaquia son dos estados cristianos ortodoxos de lengua rumana que se definen como soberanías completas, que se crean en el siglo XIV pero entran en la órbita otomana a partir de finales de este siglo.

En la época en la que se escribe el texto, Moldavia y Valaquia se desprenden de la administración directa otomana (desde el tratado de Küçük Kaynarca de 1774, que cierra la llamada primera guerra «ruso-turca»), pero se encuentran bajo régimen particular: de 1715 a 1821-22, sus soberanos son nombrados directamente por el gobierno otomano, y éste los escoge entre los súbditos rûm helenohablantes por el espacio de tres años, hecho que limita la autonomía de su poder.

Estos voivodas pertenecen a un grupo social helenohablante específico que se constituye en la segunda mitad del siglo XVII, y más tarde se llamarán fanariotas, a partir del nombre del barrio del Fener (en griego Фavá ıl(ov), en Estambul donde se concentra la mayoría de sus residencias. Este grupo social tiene características propias, que paso a definir.

El gobierno otomano juzga oportuno poner a estos fanariotas a la cabeza de esos estados, donde ellos y su corte (donde el elemento fanariota predomina sobre el elemento puramente moldo-valaco) hacen contrapeso, desempeñando su papel cristiano, al expansionismo ruso vecino, expansionismo apoyado por el Estado habsburgo (a la batuta del Emperador del Santo Imperio, rey de Bohemia y de Hungría-Croacia). 
Xavier. Agati: La romanidad oriental moderna: un testimonio sobre el papel...

\section{3) La Gran Iglesia}

Por razones de comodidad, he decidido utilizar el término Gran Iglesia para definir la Iglesia calcedonia ortodoxa a menudo llamada griega o bizantina (también, de Constantinopla). Lo hago siguiendo el ejemplo del autor, y siguiendo toda la tradición bizantina.

Inicialmente, este término designa, de forma abstracta, a la Iglesia tal y como se define en el Concilio de Calcedonia de 451, y se opone a las demás Iglesias orientales que no aceptaron las posiciones de dicho Concilio. Más tarde, llega a referirse únicamente a la iglesia ortodoxa griega o bizantina, en tiempo de la separación con la Iglesia romana.

En la época del texto estudiado la Gran Iglesia reúne tan sólo a los helenohablantes del Imperio otomano, a los búlgaros, los serbios y montenegrinos, a una parte de los albaneses, a los rusos, los moldavos, los valacos y los georgianos.

\section{4) Estambul y Pâdişâh}

En el texto, Constantinopla es llamada, de acuerdo con toda la tradición

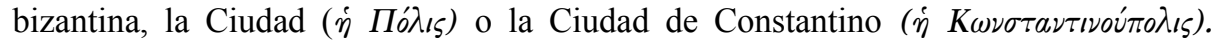
Estambul no es sino la formulación turca otomana del griego $\sigma \tau \dot{\nu} \nu \Pi_{o} \lambda_{l}(\nu)$ : en la Ciudad, a la Ciudad.

Por otra parte, en lugar del término Sultán, me inclino por una elección otomanista y opto por el término Pâdişâh, pues Sultân se empleaba sobre todo en lengua otomana para indicar la pertenencia a la sangre imperial (y por esta razón, lo empleaba la titulatura de los miembros de la familla imperial). El autor emplea a

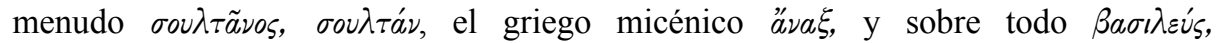
emperador, palabra que designa a los emperadores de Roma, de Bizancio y a los emperadores de Persia en toda la tradición griega. 


\section{II- Posición y papel de la Gran Iglesia en el Imperio otomano en el siglo XVIII}

\section{1) Prerrogativas de la Gran Iglesia en el Imperio otomano ${ }^{1}$}

\section{a- El patriarca de Constantinopla, jefe otomano de la Nación rûm}

En este apartado no estudiaré todas las fuentes que esclarecen la génesis del poder en el seno del poder otomano del Patriarca, jefe de la Gran Iglesia, desde las entrevistas fundadoras del Pâdişâh conquistador de la ciudad, Sultân Mehmet II, con el primer patriarca del período otomano, Genadio, despues de la Conquista.

A pesar de su interés, tampoco estudiaré las razones de la posición antiunionista del primer patriarca otomano, es decir, el repudio de la posibilidad de una cruzada contra los otomanos ${ }^{2}$ gracias a la unión de la Gran Iglesia con la Iglesia romana. Tampoco voy a detenerme en las negociaciones que tuvieron lugar la víspera de la Conquista entre los soberanos otomanos y ciertos miembros de la Gran Iglesia, aunque es cierto que éstas fueron parte del cimiento de las prerrogativas futuras de esta Iglesia ${ }^{3}$.

Sin embargo, vale decir, aquí, hasta qué punto el papel del patriarca del siglo XVIII en el Imperio otomano difiere del que desempeñaba éste durante el Imperio bizantino.

Aun antes de las conquistas árabes de las provincias que dependían de los patriarcas de Alejandría, de Antioquía y de Jerusalén, la posición del patriarca de Constantinopla era ya preponderante, desde un punto de vista honorífico, sobre los otros tres patriarcas orientales, después del Concilio de Constantinopla de 381 (canon

${ }^{1}$ Cfr. T. H. Papadopoullos, Studies and Documents relating to the History of the Greek Church and People under Turkish Domination, Biblioteca Graeca - Aevi Posteriores - I, Brussells, 1952. Este estudio se basa en un buen número de historiadores helenohablantes de todo el período otomano (entre ellos A. Komninós Ipsilántis), y en varios documentos de los archivos otomanos de los Pâdişah: fermân (firmán), berât, Hatt-ı Şerîf o Hümâyûn. Cfr. capítulo 3 de

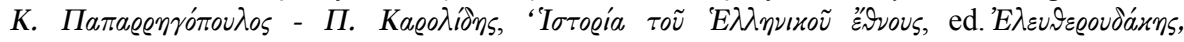
Åกิขal, 1925.

${ }^{2}$ En cuanto a la hostilidad de Genádio para con la unión de la Iglesia de Constantinopla, cfr. L. Petit, X. Siderides, M. Jugie, Oeuvres complètes de Scholarios, 8 vol., Paris, 1928-1936, vol. VI, p. 178; vol. III, pp. 152-165; vol. IV, p. 464. En su Confessio fide explica las razones religiosas y dogmáticas de su posición, cfr. op. cit., vol. III, pp. 434-452 y 453-458, sobre

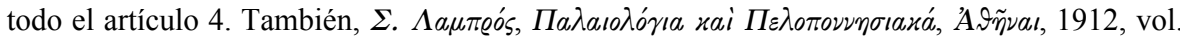
II, pp. 89-105 y pp. 120-121.

${ }^{3}$ Sobre el temor que sintiera Sultân Mehmet II por una cruzada sublevada por el Papa, cfr.

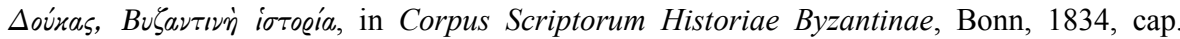
XXXI p. 215 (otra ed. in Migne, Patrologia Graeca, tomo 157, Paris, 1866). Sobre las negociaciones entre otomanos y miembros de la Gran Iglesia en la vigilia de la conquista, cfr.

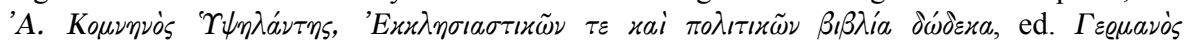

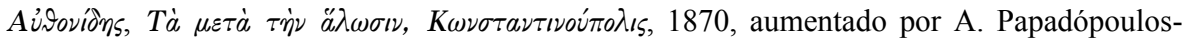
Keramévs 1909, pp. 50-52, y D. Cantemir, The History of the Growth and Decay of the Ottoman Empire (traducido del latín por L. Tendal), London, 1756, p. 104. 


\section{Xavier. Agati: La romanidad oriental moderna: un testimonio sobre el papel...}

3) y sobre todo del concilio de Calcedonia de 451 (canon 28), donde había recibido el título de Patriarca ecuménico, como jefe de la Iglesia calcedonia ortodoxa griega recientemente definida.

Su posición se refuerza, bajo el Imperio otomano, ante los patriarcas orientales y todos los súbditos rûm del Imperio otomano. Dado que, como se ha dicho ya, el estatuto civil de cada súbdito del Imperio otomano estaba determinado por su confesión religiosa, el patriarca de Constantinopla, simple referente religioso supremo en el Imperio bizantino (a pesar de estar asociado al poder), se convierte también en responsable temporal de todos los rûm, y, en consecuencia, recibe una competencia en jurisdicción civil sobre ellos.

En el sistema de los dignatarios otomanos, lleva el título de Millet başı, es decir, jefe de nación. Así, se encuentra posicionado en relación de colegiatura con el Millet başı de los cristianos no calcedonios, o sea, el patriarca armenio, el Millet başı de los judíos (el Haham başı), y hasta el Millet başı de todos los musulmanes, es decir, el Şeyh ül islâm o Gran müfti de Estambul.

Sin embargo, en los hechos, el poder del patriarca de Constantinopla no guarda su sentido pleno sino hasta la emergencia del grupo social de los fanariotas, durante el siglo XVII. De hecho, a partir de este período, toda la Gran Iglesia atraviesa una crisis y pierde la mayor parte de sus poderes efectivos, eclesiásticos y civiles, pero no debido directamente al gobierno otomano en sí, sino a la emergencia del grupo social de los fanariotas integrados en el gobierno.

\section{b- Los cimientos del poder del patriarca en el período otomano}

Existía probablemente un berât (diploma otomano de investidura) o un

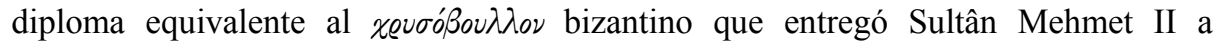
Genadio, (documento cuyo paradero se desconoce, pero cuya existencia parece probable), que estipulaba las prerrogativas y sobre todo la autonomía y la inmutabilidad del patriarca de Constantinopla.

El estudio de las fuentes contemporáneas ha mostrado que a Mehmet II y sus sucesores les convenía otorgar estas ventajas, por la organización y la reconciliación, por mantener la paz y la cohesión del Imperio ${ }^{4}$. En esto, el pragmatismo prevaleció ante las consideraciones relativas a la ley musulmana.

La consecuencia inmediata de este nuevo poder adquirido por el patriarca de Constantinopla es que los otros tres patriarcas ortodoxos orientales (de Alejandría, Antioquía y Jerusalén) pasan a someterse a él en la práctica: él nombra los candidatos al trono y al poder administrativo que los precede.

\footnotetext{
${ }^{4}$ Según N. Iorga, otorgar una autonomía importante a la Iglesia de Constantinopla hubiese permitido al gobierno otomano utilizar las estructuras administrativas ya establecidas, que se basaban en provincias eclesiásticas. Cfr. Geschichte des Osmanischen Reiches nach den Quellen dargestellt, Gotha, 1909-1912, vol. II, libro I, cap. I.
}


vol. IX, Å $\tilde{\eta} v a l, 1936$, pp. 103-166. 
Byzantion Nea Hellás 28, 2009: 127-164

No presentaré aquí el estudio detallado de las prerrogativas, de los deberes y del poder del patriarca durante los aproximadamente dos siglos de autonomía real, como se describe en los berât de investidura de los patriarcas ${ }^{6}$. Tampoco expondré los detalles de las prerrogativas del Sínodo, órgano que cobra su importancia administrativa en el período otomano ${ }^{7}$.

No obstante, es necesario subrayar dos importantes limitaciones, posteriores a la Conquista, a las prerrogativas iniciales garantizadas al patriarca en el documento mencionado: el Pâdişâh puede deponerlo para «hacer elegir a otro» ${ }^{8}$, y el Sínodo recibe el derecho de presentar quejas sobre el Patriarca ante el Pâdişâh, que estudia la queja ante el Divân, instancia política suprema del gobierno otomano': estas

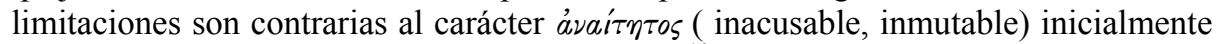
estipulado en el documento de Sultân Mehmet II ${ }^{10}$.

Por otro lado, hubo violaciones de la autonomía del patriarca a las que se refieren con frecuencia los autores helenohablantes del período otomano posterior a la Conquista, es decir, injerencia del poder otomano en los asuntos de la Iglesia. Pero, puede decirse que este fenómeno era bastante común en el Imperio bizantino. Además, si bien se trata de una violación del principio de autonomía de base, no constituye una abolición. De hecho, se puede afirmar que, en materia doctrinal, el poder otomano nunca intervino en las posiciones del patriarca, a diferencia de los soberanos bizantinos ${ }^{11}$.

Un rasgo mayor del período otomano es la helenización de los componentes moldo - valaco, serbio y búlgaro de la Gran Iglesia, favorizada por el gobierno otomano a lo largo de su historia. La lengua litúrgica griega prevalece sobre todas las otras. Esta homogeneización se observa particularmente en el momento en el que el patriarcado serbio de Peć, creado para dirigir a los serbios, queda suprimido en 1766, como en 1768 el arzobispado autocéfalo búlgaro de Ohrid. Ambos pasan a someterse bajo la tutela directa del patriarca de Constantinopla.

\section{c- La Gran Iglesia, referente cultural}

El hecho que la Gran Iglesia se convirtiera en el único órgano oficial representativo de toda la comunidad helenohablante, heredera religiosa y cultural del Imperio bizantino, hace de ella el referente cultural bizantino helenohablante por excelencia, ya sea religiosa, filosófica, literaria, histórica y hasta política durante todo el período otomano.

${ }^{6}$ D’Ohsson, Tableau général de l'Empire Ottoman (traducción en francés), Paris, 1824, vol. V, pp. 120-139.

${ }^{7}$ T. H. Papadopoullos, op. cit., pp. 39-48.

${ }^{8}$ T. H. Papadopoullos, op . cit. cita a d'Ohsson, p. 29.

${ }^{9}$ Ibid., p. 38.

${ }^{10}$ Ibid., pp. 31-32.

${ }^{11}$ G. Veinstein, Les provinces balkaniques (1606-1774), in Histoire de l'Empire Ottoman, sous la direction de R. Mantran, Paris, 1989, p. 338. 


\section{Xavier. Agati: La romanidad oriental moderna: un testimonio sobre el papel...}

Basta con echar un vistazo a la cantidad considerable de obras escritas en griego durante todo este período para sorprenderse no sólo de su abundancia, sino además de su naturaleza.

Toda la literatura griega del período otomano está lejos de ser producida en el interior de las fronteras otomanas: muchas son editadas en los territorios anteriormente bizantinos que permanecen bajo la dependencia de Venecia, en el Estado habsburgo y en Rusia. Pero estos territorios permanecen unidos, directa o indirectamente, por su organización eclesiástica, al patriarcado de Constantinopla ${ }^{12}$.

Los temas tratados muestran el lazo entre la Gran Iglesia y la producción literaria: los temas tratados con mayor frecuencia son los relativos a la teología, a la patrística y a la filosofía (sus autores son de hecho eclesiásticos), también la política y la historia $\mathrm{y}$, finalmente, la literatura ${ }^{13}$.

\section{2) La Gran Iglesia ante la emergencia de los fanariotas}

Entre finales del siglo XVII y el siglo XVIII, el Sínodo y el patriarca se encuentran confrontados al ascenso de los fanariotas que, poco a poco, los despojan de sus poderes mediante la influencia que ejercen en la élite musulmana en el poder. Podría hablarse de desposeimiento de las prerrogativas históricamente garantizadas (y, sin duda, ya disminuidas) por el poder otomano a los representantes de la Iglesia por una élite helenohablante integrada al poder otomano.

\section{a- Los fanariotas}

En el texto traducido, la palabra fanariota nunca aparece. Sólo entra en uso de forma efectiva en el siglo XIX.

Constituido por la fortuna acumulada (gracias al comercio), por las alianzas y por el deseo de mejorar su condición, este grupo se caracteriza por estrategias políticas comunes: utiliza a la Iglesia como palanca, haciéndose imprescindible y hasta imponiéndosele y, simultáneamente, obtiene puestos políticos muy importantes

\footnotetext{
${ }^{12}$ La mayoría, sin duda, se edita en Venecia y Viena, pero también en Estambul, Leipzig y San Petersburgo u otras ciudades europeas y otomanas. En cuanto al papel del Exarca patriarcal (Arzobispo de Filadelfia) que dependía del patriarcado de Constantinopla en los territorios



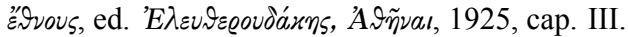




ediciones anotadas de textos griegos del siglo XVIII, hasta entonces inéditos, cfr. E. Legrand, Bibliothèque grecque vulgaire, Paris, 1880; Bibliographie hellénique ou description raisonnée des ouvrages publiés par les Grecs, XVIIIème siècle, 2 vol., ed. L. Petit, H. Pernot, Paris, 1894-1903. Para un estudio general reciente de la historiografía griega a partir del siglo


Para los repertorios de manuscritos inéditos, cfr. M. Richard, Répertoire des Bibliothèques et des Manuscrits grecs, Publications de l'Institut de Recherche et d'Histoire des Textes, no 1, Paris, 1948.
} 
en el gobierno otomano, fuentes de influencia y medios de presión. Así, el grupo se desarrolla en dos planos, el eclesiástico y el político. Utiliza el griego como lengua principal de comunicación, aun cuando su carácter étnico es compuesto, pues las grandes familias fanariotas son de origen italiano, griego-bizantino, moldavo, valaco, albanés y dálmata. Algunas familias reciben un nombre turco otomano como el de los Karaca (Karadzás), los Sütçü (Soútzos), los Hançerli (Khandzerlís) ${ }^{14}$.

En la lectura del texto que nos incumbe, el cursus honorum de los fanariotas insignes a finales del siglo XVIII aparece de forma clara. Si se deja a un lado las carreras puramente eclesiásticas, la meta del fanariota es la de llegar a ser primero Gran logoteta de la Gran Iglesia o Intérprete del mar.

El puesto de Gran logoteta de la Gran Iglesia es un puesto de oficial


distintos: uno eclesiástico y el otro civil, que cambia considerablemente de fisionomía $\mathrm{y}$ hasta de nombre durante todo el período otomano ${ }^{15}$.

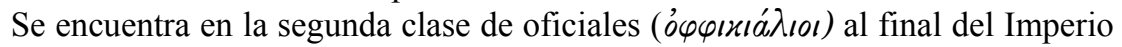
bizantino, y pasa, progresivamente, al primer rango de la primera clase adquiriendo el adjetivo Gran que sólo poseía un puesto exclusivamente civil durante el período bizantino. A finales del siglo XVIII llega a poseer el mayor poder de los miembros

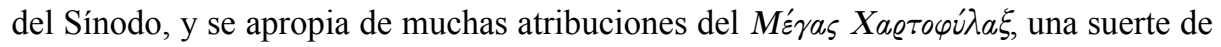
secretario general del patriarca en los asuntos judiciales eclesiásticos.

Después de la reforma de 1741 que impone la decadencia de hecho de los

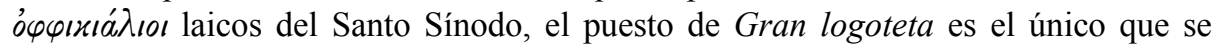
mantiene realmente. Sin embargo, su papel se reduce al de servir de lazo de unión entre el patriarca y el gobierno otomano.

El puesto de Intérprete del mar es el del jefe de los intérpretes que dependían del Kaptan-ı Deryâ, ministro otomano de la Marina. Este puesto tiene la ventaja de ser el escalón para convertirse en Intérprete principal del Divân Augusto.

El Intérprete principal del Divân Augusto es el puesto mayor del cuerpo oficial de intérpretes; al término de su carrera puede acceder al puesto supremo, el de voivoda de Valaquia o de Moldavia, y reinar con su corte sobre estos Estados.

${ }^{14}$ E. Rizos-Ragkabes, Le Livre d'or de la noblesse phanariote en Grèce, Roumanie, Russie, Turquie, par un Phanariote, Athènes, 1892.

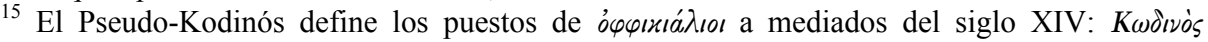

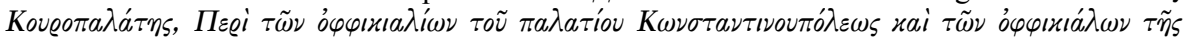

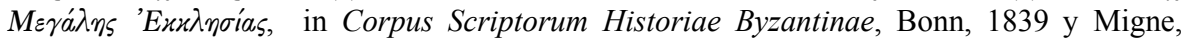
Patrologia Graeca, vol. 157, Paris, 1866. Crisanto, patriarca de Jerusalén, describe estos

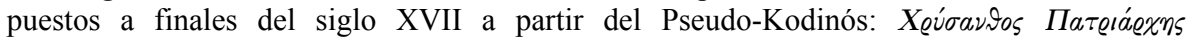

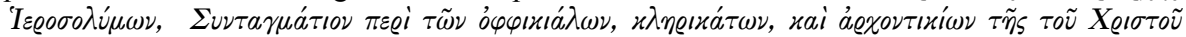

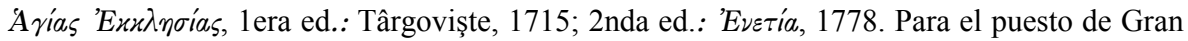

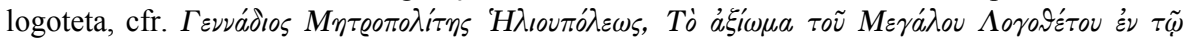

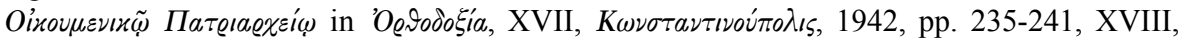
1943, pp. 178-180, y aquí, nota 19. 


\section{Xavier. Agati: La romanidad oriental moderna: un testimonio sobre el papel...}

Durante las guerras del siglo XVIII, los fanariotas son, al mismo tiempo, el grupo social al servicio del Imperio otomano y la entidad particularmente permeable a la penetración de ideas recibidas del movimiento de las Luces en Europa; ideas que transitan por el medio de los grandes poderes enemigos vecinos de Moldavia y Valaquia: la Rusia de Catalina II y el Estado habsburgo de José II.

Las dignidades asumidas por los fanariotas, y su conocimiento del poder, los hace expertos en la explotación del crédito ante las más altas dignidades musulmanas y en el uso de la presión. El texto estudiado deja entrever que dicho crédito puede llegar a la manipulación de dignatarios musulmanes tan importantes como el Gran visir, jefe del Estado otomano por delegación, y no sólo en lo relativo a los asuntos de la Nación rûm del Imperio.

$\mathrm{N}$. Iorga considera la aparición de esta clase como un resurgimiento del poder civil bizantino, como una forma de revancha bizantina sobre la historia. «Viniendo de todas las provincias del Imperio, formaron, juntos, una grecidad bizantina única, muy diferente de la grecidad revolucionaria, de espíritu nacional, que ganará terreno sobre el pedazo de tierra griega que había cobrado libertad después de $1821{ }^{16}$



A partir de la segunda mitad del siglo XVII, los fanariotas sacan provecho de una situación ya establecida cuando entraron al poder. Esta situación era la tendencia a la infiltración de laicos, y no de jerarcas, a puestos llamados de oficiales

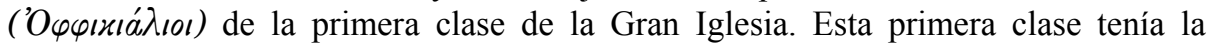
particularidad de dar derecho a sus miembros de residir en el Sínodo. La infiltración en cuestión, en principio prohibida por la tradición bizantina ${ }^{17}$, se atestigua desde mediados del siglo XIV, es decir, antes de la Conquista, y muchas son las pruebas al final del siglo XVII y en el siglo XVIII ${ }^{18}$. Esta infiltración produce un cisma en los


ocupan los eclesiásticos. Es seguro que este fenómeno se desarrolla verdaderamente en época otomana y conoce su apogeo con los fanariotas ${ }^{19}$.

\footnotetext{
${ }^{16}$ N. Iorga, Byzance après Byzance, Paris, 1992, p. 237.

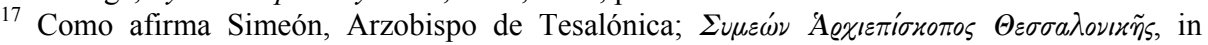
Migne, Patrologia Graeca, vol. 155, Paris, 1868, col. 465, cap. CCXVVIII.

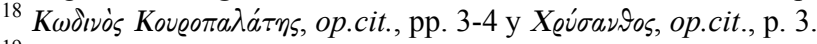


op.cit., p. 71 y T. H. Papadopoullos, op.cit., pp. 80-81. La evolución del puesto de Gran



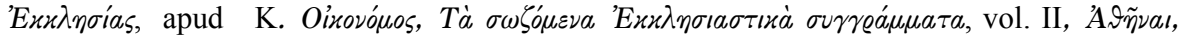

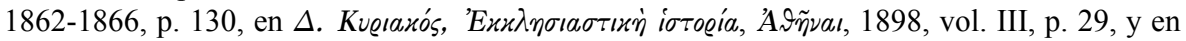

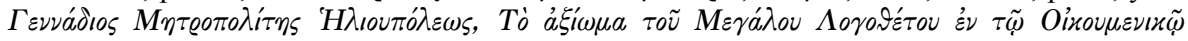

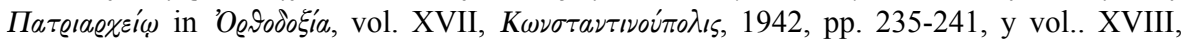
1943, pp. 178-180. La del Gran eclesiarca se encuentra en T. H. Papadopoullos, op. cit., p.

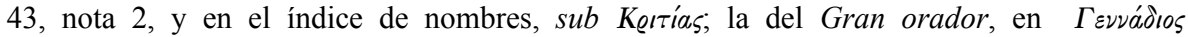


Un firmán de reacción obtenido en 1741 contra esta influencia, ocasiona, en los años siguientes, una reforma completa del Sínodo que llega a un sistema que vuelve a dar la responsabilidad de los asuntos materiales de la Iglesia sólo a las manos de cinco jerarcas que residen en Estambul, llamados $\gamma \varepsilon \varrho o \nu \tau i \sigma \mu o ́ s$, que luego llegan a ser ocho, lo que no excluye la participación de otros jerarcas como miembros no permanentes $^{20}$. Sin embargo, el patriarca pierde definitivamente su poder efectivo porque, si la gestión administrativa corresponde a los eclesiásticos, él se somete por completo al Sínodo recientemente constituido y pasa a desempeñar tan sólo el papel de presidente ${ }^{21}$.

En realidad, el único poder verdadero recuperado por los jerarcas del Sínodo es la elección del patriarca.

La influencia de los fanariotas sigue siendo tan fuerte como antes, a pesar de haber dejado de residir en el Sínodo, debido a las presiones que ejercían continuamente sobre los jerarcas. Sabemos que ciertos fanariotas llegan a dominar por completo las nominaciones a dignidades eclesiásticas ${ }^{22}$, y a deponer al patriarca Serafín II en $1760^{23}$. Mantienen su influencia hasta la guerra de independencia de Grecia.

Athanásios Ipisilántis describe la situación del patriarca en la segunda mitad del siglo XVIII como «insoportable debido a las dificultades administrativas y a asuntos absurdos que surgen en las relaciones entre el patriarca y las personas en altas posiciones, rûm u otros, y, peor aún, porque él ve venir su deposición, generalmente acompañada de un exilio» ${ }^{24}$. El patriarca se encuentra atrapado entre el Sínodo, los fanariotas influyentes y los dignatarios musulmanes.

A pesar de las críticas de sus contemporáneos y de sus súbditos en Moldavia y en Valaquia, la acción de los fanariotas se describe como positiva desde cierto punto: la vitalidad de las letras griegas, el desarrollo intelectual según un tipo de enseñanza bizantina y occidental moderna a la vez, que los fanariotas favorizan en los dos países que gobiernan en ese momento.

\section{c- La acción de los voivodas fanariotas en favor de las letras griegas, de la tradición cultural bizantina y de ideas occidentales}

Los estudios realizados sobre los fanariotas voivodas otorgan una imagen muy contrastada de su reinado. En su conjunto, la historiografía rumana contemporánea guarda los aspectos negativos, mostrando el retroceso global en el plan económico y



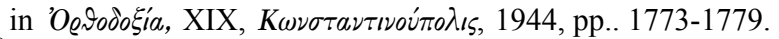

${ }^{20}$ T. H. Papadopoullos, op. cit., pp. 50-58.

${ }^{21}$ Ibid. p. 58.


XII, p. 534.

${ }^{23}$ T. H. Papadopoullos, op.cit., p 55.

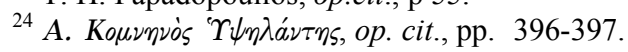




\section{Xavier. Agati: La romanidad oriental moderna: un testimonio sobre el papel...}

hasta cultural, en comparación con el siglo XVII. Se insiste en cuánto explotaban económicamente los fanariotas a la población ${ }^{25}$.

No obstante, en el campo de la administración y la fiscalidad, se reconoce que ciertos voivodas como Konstantínos Mavrokordátos iniciaron reformas modernas sobre el modelo de Rusia y del Imperio habsburgo ${ }^{26}$.

En Bizancio después de Bizancio, por otro lado, N. Iorga insiste en el papel positivo de ciertos voivodas fanariotas de Moldavia y Valaquia en el campo de la difusión de la cultura bizantina y de las ideas occidentales en sus Estados.

El objeto de su libro es definir la perennidad del espíritu bizantino. Según indica, este espíritu sobrevive realmente durante todo el Imperio otomano y expira en lo que llama la verdadera caída de Constantinopla: la guerra de independencia de Grecia. Lamenta que los destinos de los griegos, de los rumanos, serbios, montenegrinos y búlgaros se hayan separado en ese momento, y que Aléxandros Ipsilántis, nieto del voivoda de Moldavia del mismo nombre, haya fracasado en dirigir una revolución común apuntando a la restauración de un Bizancio cristiano ${ }^{27}$. El acceso a las independencias separadas de Grecia (1830), Serbia, de Montenegro y de Bulgaria (1878), y luego de Rumania (1880) constituye para él la verdadera muerte de Bizancio.

Según G. Veinstein, algunos príncipes fanariotas fueron escritores de gran talento, y la renovación intelectual proviene de la clase de los fanariotas, transformando la esclerosis que había mantenido el patriarcado ${ }^{28}$.

El papel de difusor de la cultura bizantina en Moldavia y Valaquia se observa en particular con la fundación de las Academias de Yaşi y de Bucarest en el siglo XVII. De hecho, es, sobre todo, en el siglo XVII que se constata el renacimiento intelectual que N. Iorga llama «renacimiento bizantino» ${ }^{29}$. Como ejemplos de iniciadores de este renacimiento, hace figurar a muchos intelectuales especialistas en literatura $\mathrm{o}$ en filosofía bizantina y antigua como K. Loukáris, T. Koridallévs ${ }^{30}$, Aléxandros Mavrokordátos ${ }^{31}$, historiador, gramático y autor de una tesis sobre la circulación de la sangre ${ }^{32}$. Para reunir los letrados de su época, Konstantínos Kantakouzinós funda la Academia de Bucarest sobre el modelo de la universidad de

${ }^{25}$ Cfr. G. Veinstein, op. cit, p. 331, y globalmente, M.-P. Zallony, Essai sur les Phanariotes, Marseille, 1824, y V. Georgescu, The political ideology of the Rumanian Boyards in the XVIIIth century, East European Quaterly, VII, N 1, Boulder, Colorado University, 1973.

${ }^{26}$ G. Veinstein, op. cit., p. 312.

${ }^{27}$ N. Iorga, Byzance après Byzance, p. 250.

${ }^{28}$ G. Veinstein, op. cit., p. 339.

${ }^{29}$ N. Iorga, op. cit,, pp. 206-225.



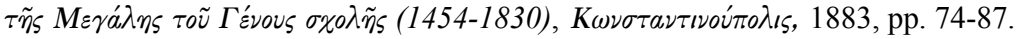

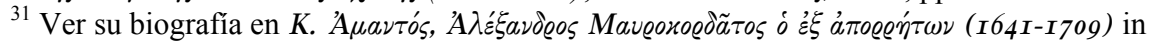

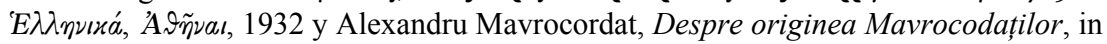
Arhiva ştiinţifice şi literare, Iaşi, 1894, p. 294 y sgtes.

${ }^{32}$ G. Veinstein, op. cit., p. 339. 
Padua, pero con el griego como lengua de aprendizaje y con la inclusión, en el programa, de autores bizantinos. Esta academia fue presidida por personalidades como S. Kimenítis, especialista de Isócrates y de Aristóteles ${ }^{33}$.

La educación bizantina que se dispensa en la Academia impregna el recorrido de varios voivodas como Dimitrie Cantemir, autor de las Incrementa atque decrementa aulae otomanicae y de la Descriptio Moldaviae, traductor del filósofo Heinecio, seguidor del historiador Vico y precursor de Montesquieu en la teoría de las «Revoluciones de los Imperios», como Konstantínos Doúkas, u otros escritores prolijos como K. Dapóntes.

Otras escuelas siguieron el modelo de estas academias, en particular las llamadas «escuelas griegas», como la de Yaşi en 1714.

Los programas de las academias y de las escuelas comprendían el estudio de los antiguos, de la literatura sagrada (Gregorio Nazanceno y Sinesio), y la de los bizantinos. Se seguía el programa de enseñanza de tipo bizantino en varios sentidos.

El siglo XVIII continúa esta evolución, pero incluyendo en los programas las ideas de las Luces europeas. G. Veinstein califica los programas de las escuelas de este siglo como la «síntesis de la tradición griega y de las nuevas ideas de

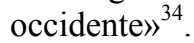

Bajo los voivodas fanariotas, los programas de enseñanza de las Academias de Moldavia y Valaquia se renuevan difundiendo las letras y la enseñanza de lenguas europeas, en especial el francés.

Es indiscutible que ciertos voivodas hayan favorizado la introducción de las ideas de las Luces en el Imperio otomano ${ }^{35}$. En el siglo XVIII, la imitación de Bizancio es menos fuerte, la de Europa, en cambio, lo es más. Al estudiar las obras de Evgénios Voulgáris, profesor en varias escuelas, o de D. D. Filippídis, se constata que la filosofía francesa reemplaza la bizantina: el programa de las nuevas escuelas de ciencias y de lenguas occidentales fundadas por Grigórios Aléxandros Gkíkas y Aléxandros Ipsilántis lo demuestran ${ }^{36}$.

Por otro lado, los fanariotas de Estambul mandan a sus hijos a formarse en Occidente (sobre todo en Italia): y de este modo promueven la introducción de las ideas occidentales que se encontraban mezcladas a la tradición bizantina.

Pero el período fanariota es también un período de cambio legislativo ${ }^{37}$. Los fanariotas constituyen e imponen códigos legislativos, sobre todo escritos en griego, siguiendo las disposiciones mencionadas en las fuentes de derecho bizantino, las

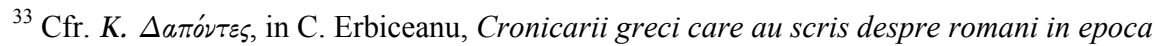
fanariota., Bucureşti, 1888, p. 17.

${ }^{34}$ G. Veinstein, op. cit., p. 339.

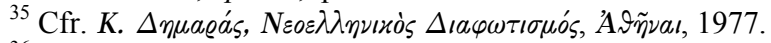

${ }^{36}$ N. Iorga, op. cit., p. 225.



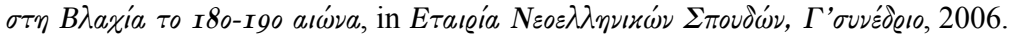


Xavier. Agati: La romanidad oriental moderna: un testimonio sobre el papel...

$B \alpha \sigma \iota \lambda l \kappa \alpha^{38}$. Apoyándose en el modelo autocrático bizantino, los voivodas fanariotas, en su legislación, aparecían a menudo como monarcas absolutos, hasta tiranos, e inspiraban antipatías en Moldavia y Valaquia donde debían encarar la mentalidad feudal de los boyardos (clase poseedora moldava y valaca), cuando las ideas de las Luces aparecieron, con deseo de reformar el pueblo ${ }^{39}$.

Varias fuentes subrayan el papel positivo que el voivoda de Valaquia y luego de Moldavia, Aléxandros Ipsilántis, tuvo en el campo cutural y legislativo. Este voivoda (que no debe confundirse con su célebre nieto, quien desempeñó un papel impulsador en la revolución de independencia griega, ni con el autor, que fue familiar suyo) hizo obligatoria la enseñanza del francés en las escuelas, con la inquietud de introducir las ideas de las Luces en Moldavia y en Valaquia. N. Iorga lo presenta como el defensor de lo que él llama el «bizantinismo modernizado y occidentalizado» ${ }^{40}$.

$\mathrm{Su}$ obra magna es el grupo de leyes llamado Pravilniceasca condică, en griego

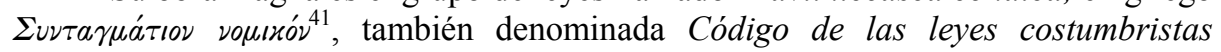
bizantinas, de 1780, cuyo objetivo es enmendar las leyes fiscales, administrativas, judiciales y políticas, refiriéndose al derecho bizantino ${ }^{42}$.

\section{III- Presentación de los Asuntos eclesiásticos y políticos: la obra y su autor}

\section{1) EI manuscrito, las ediciones, la lengua}

\section{a- Las ediciones sucesivas}

De la totalidad de la monumental obra de Athanásios Komninós Ipsilántis, compuesta de doce libros, sólo los tres últimos en orden cronológico fueron editados

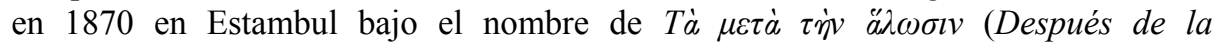
Conquista) por el superior del Monasterio de Santa Catalina del Sinaí en Egipto: Germán Avthonídis. Se trata de los libros VIII, IX y X.

El texto que publica Germán Avthonídis se establece directamente a partir del manuscrito original al que faltaban dos partes en el momento de la edición, partes que fueron halladas por A. Papadópoulos-Keramévs y añadidas a la edición de 1870, que

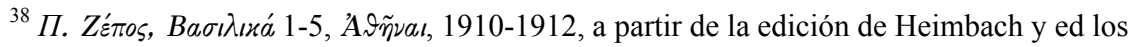
complementos de Z. von Lingethal, E. Ferrini y J. Mercati.

39 Cfr. P. Zepos, La politique sociale des princes phanariotes, in Balkan Studies 11, Thessaloniki, 1970, p.81 y sgtes.

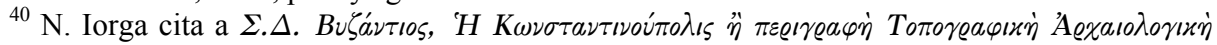

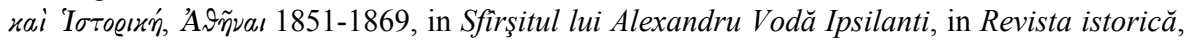
XX, Bucarest, 1934, pp. 305-307.

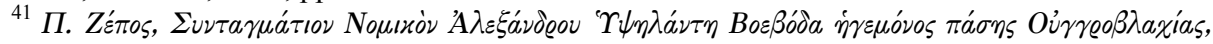

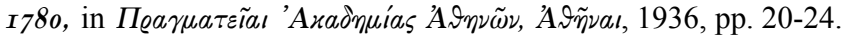

${ }^{42}$ Ibid, cap. XVI. 
se reditó en $1909^{43}$.

\section{b- El manuscrito del Cairo}

El texto establecido por Germán Avthonídis se edificó a partir del manuscrito autógrafo único de Ipsilántis, que hasta el día de hoy permanece en propiedad del Monasterio de Santa Catalina del Sinaí, en el barrio de Juvania ${ }^{44}$, en el viejo Cairo, en Egipto, hoy trasladado al barrio Midan el Daher.

Para explicar la presencia del manuscrito en el Cairo, Germán Avthonídis dice saber que la hija del autor ${ }^{45}$ había prestado el manuscrito a K. Constancio II, entonces arzobispo del Sinaí, que deseaba inspirarse para escribir su propio libro ${ }^{46}$.

La elección, de Germán Avthonídis, de los libros VIII, IX y X se explica por el valor histórico particular de estar constituídos, en gran parte, de sucesos vividos o vistos personalmente por el autor. Puesto que los dos últimos libros del conjunto, el XI y el XII son libros temáticos y no libros de acontecimientos, los tres libros precedentes constituyen el final de la cronología.

Athanásios Ipsilántis escribe con el objetivo de constituir nada menos que una historia articulada de los emperadores de Roma y de los patriarcas de la Iglesia universal a partir de Julio César hasta su época, extendiendo la legitimidad imperial romana, de forma explícita, en la persona del patriarca de Constantinopla y, en parte, en la de los sultanes otomanos, presentando compilaciones de otras obras existentes para los períodos anteriores a su época. Se establece, de entrada, el lazo entre el Imperio romano y su continuación explícita en la Pentarquía cristiana constituida por los cinco patriarcados iniciales de la Iglesia universal: El Papa de Roma, el patriarca ecuménico de Constantinopla, el patriarca o Papa de Alejandría, el patriarca de Antioquía y el de Jerusalén.

El objetivo del autor se expone de forma explícita en su prólogo ${ }^{47}$ : entregándose a la redacción de este colosal trabajo histórico, Ipsilántis quiere servir a la Iglesia ortodoxa, desea hacer obra didáctica, y sobre todo proselitista, describiendo

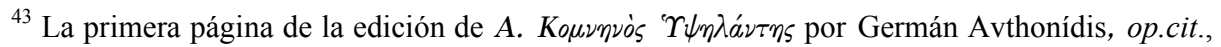
menciona la publicación de A. Papadópoulos-Keramévs de ciertas partes faltantes de la edición de Germán Avthonídis en Documente privitoare la Istoria Românilor, culose de E. Hurmuzaki, tomo 13, Bucuresti, 1909. Pero una parte importante de esos elementos faltantes fue añadida a la propia edición de Germán Avthonídis. Cfr. la noticia de A. Papadópoulos

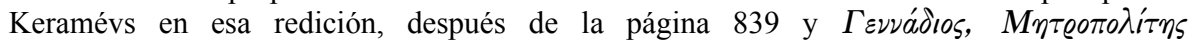

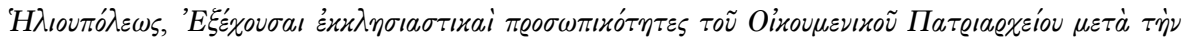

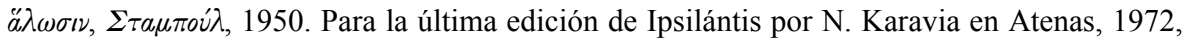



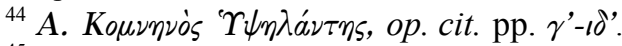

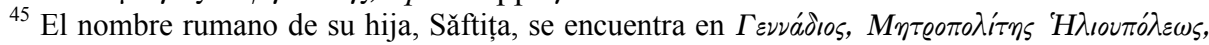

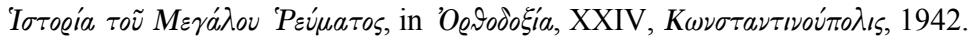



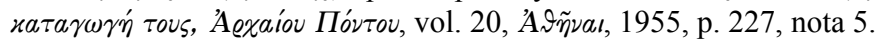

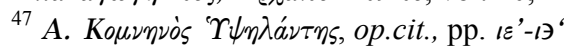




\section{Xavier. Agati: La romanidad oriental moderna: un testimonio sobre el papel...}

la «justa sucesión de los patriarcas» de la que desea preconizar «las cualidades ortodoxas», es decir, conformes a la justa fe cristiana.

El texto se dirige explícitamente a un público herético cuya identidad no se precisa. Para el autor, las cuestiones políticas están englobadas dentro las eclesiásticas: toda la obra está dividida según los patriarcas, y las subdivisiones se hacen según los soberanos temporales.

El objeto del último libro de la cronología, el X, son los últimos veintiún años anteriores a 1789: durante este período el autor se encuentra en Estambul, ha atravesado por una serie de sucesos que evoca, comenta y en los que se pone en escena a sí mismo ${ }^{48}$.

\section{c- La lengua}

La mayor parte de la obra está ecrita en griego arcaizante, la última forma de griego antiguo fijada siguiendo el modelo bizantino a partir de la xoıvń de los padres de la Iglesia oriental del siglo IV. El prólogo está escrito en griego aticista, basado en la lengua ateniense del siglo $\mathrm{V}$ a. C., y hay en la obra algunas particularidades debidas al dialecto oral moderno de Estambul, pero arcaizadas como de paso.

Pero la verdadera particularidad de esta lengua es su carácter compuesto: las palabras turcas otomanas la dislocan completamente, se integran completamente en el conjunto, sin contar las palabras rumanas. A veces, frases enteras de turco otomano se mezclan al conjunto.

\footnotetext{
${ }^{48}$ I. Rízos-Néroulos menciona otra obra de Athanásios Ipsilántis titulada Historia del Imperio bizantino editada en Venecia, pero sobre la que no habla ningún otro testimonio. Lo describe como interesante a pesar de la brevedad de su composición. Parece improbable de que se trate del mismo libro. Cfr. J. Rizos-Neroulos, Cours de littérature grecque moderne, 2nda ed.,

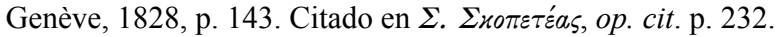




\section{2) El autor}

\section{a- Identidad y recorrido profesional ${ }^{49}$}

El autor es fanariota, pero se opone a las prácticas de este grupo. Remonta sus orígenes a la nobleza bizantina, factor de excelencia en este grupo social, y hasta la familia de los emperadores de Constantinopla; pero su familia, como la de los demás fanariotas en general, comporta también orígenes europeos exteriores a la esfera helenohablante, en particular aportes moldavo-valacos evidentes.

Nacido en 1711 en Tarabya, en el Bósforo, la vida de Ipsilántis transcurre en la mayor parte del siglo XVIII pues se supone que murió en 1789, último año que se evoca en su obra, o poco después. Después de sus estudios secundarios en Yaşi, capital de Moldavia y en Estambul, estudia filosofía y medicina en Venecia, y hace su práctica de medicina en Padua, Boloña y Florencia. Recibe su doctorado en filosofía y medicina en Padua en 1738.


una categoría de intelectuales como los que formaba la Universidad de Padua desde el siglo XVII, sumamente estimada en Estambul, Yaşi y Bucarest ${ }^{50}$.

Comienza su carrera en 1739 como jefe médico del voivoda de Moldavia Grigórios Gkíkas, y se hace nombrar, en 1744, Jefe médico (Tabîb-i Hâssa) del dignatario otomano musulmán Hoca Râgıp Mehmet Paşa. Éste cursa una carrera insigne: inicialmente gobernador (Vâlî) de la provincia del Cairo en Egipto, Nişancı başı (Jefe de archivos) en Estambul ${ }^{51}$, gobernador de la provincia de Aydın en Anatolia occidental, gobernador de la provincia de Rakka en Anatolia oriental, gobernador de la provincia de Alep en Siria, y finalmente, Gran visir del Imperio otomano $^{52}$.

Ipsilántis sigue a Ragıp Mehmet Paşa en sus puestos en esas provincias, luego vuelve a Estambul con él para su nominación como Gran visir, el 13 de diciembre de 1756.

${ }^{49}$ Debido a contradicciones importantes en las fuentes biográficas sobre el autor, refiérase

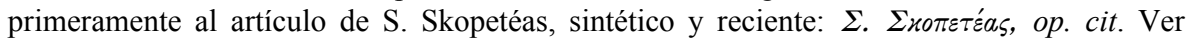
también E. Legrand, Eléments biographiques sur Athanase Comnène Ypsilantis in

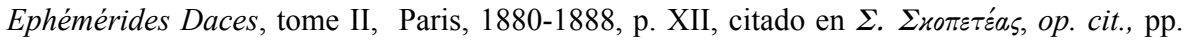

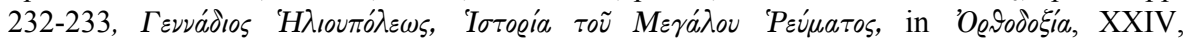

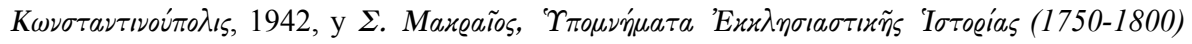

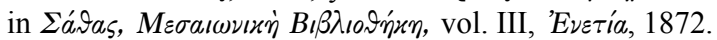

${ }^{50} \mathrm{~N}$. Iorga, op. cit., p. 210.

${ }^{51}$ Sólo el artículo Khodja Râghib Mehmed Pasha in Encyclopédie de l'Islâm, Paris, 1975-2002 (última edición), menciona este puesto en Estambul; S. Skopetéas, op.cit., y E. Legrand, op. cit., tomo II, p. XII, no menciona este puesto, quizás porque el tema es la biografía de Ipsilántis y no la de Râgip Mehmet Paşa.

${ }^{52}$ Encyclopédie de l'Islâm, artículo Khodja Râghıb Mehmed Pasha, Paris, 1975-2002 (última

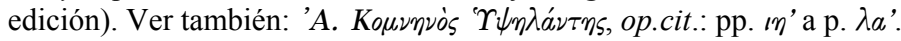




\section{Xavier. Agati: La romanidad oriental moderna: un testimonio sobre el papel...}

En 1759, Athánasios Ipsilántis es nombrado, paralelamente a su oficio de médico, Gran skeuofilax (Mźraৎ $\Sigma \varkappa \varepsilon v o \varphi v ́ \lambda a \xi$ ) de la Gran Iglesia. Pudo haber sido entonces $^{53}$ también médico del patriarca de Constantinopla, Serafín II $^{54}$.

Durante el gran visirato de Râgıp Mehmet Paşa, parece haber intentado ser Intérprete principal del Divân Augusto, sin éxito ${ }^{55}$. Por otro lado, en 1761, se tiene la certeza de que fue no sólo médico, sino también Kapı kâhya (Intendente de la puerta, es decir, representante en Estambul) del Gran visir Râgıp Mehmet Paşa ${ }^{56}$, puesto que ocupó, sin duda, durante un espacio mayor de tiempo.

$\mathrm{Su}$ servicio al dignatario musulmán duraría diecinueve años, hasta la muerte del Gran visir, en abril de 1763.

De 1764 a 1765, se convierte en Gran spătar (jefe o general de la armada) del voivoda de Valaquia Ştefan Racoviță, y recibe, en consecuencia, el título otomano de $a \breve{g} a$. Esta función se extiende hasta la nominación del siguiente voivoda, Skarlátos Gkíkas.

Luego, ocupa el puesto de Kapı Kâhya (Intendente de la puerta) del voivoda de Valaquia Grigórios Guíkas III en 1769.

Después recibe varias misiones políticas y diplomáticas: primeramente como intérprete en Crimea (quizás para el Kan Giray) en 1778; el siguiente año se encuentra en Bucarest ante el voivoda de Valaquia, familiar suyo, Aléxandros Ipsilántis.

El texto también lo muestra relacionado con los asuntos del dignatario Nikólaos Mavrogénis, entonces voivoda de Valaquia (tal vez su Kapı kâhya, Intendente de la puerta), lo que no le impide detestarlo cordialmente, como se verá más adelante ${ }^{57}$.



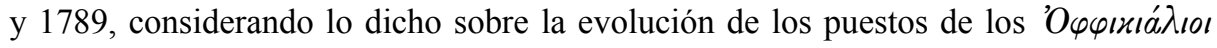
que ocupaban los laicos, pues este puesto era uno de ellos. Este punto es de importancia capital si se desea comprender todo el interés de la obra estudiada. Debe considerarse el enfoque de esta obra: a partir de esta función, Ipsilántis organiza su papel tradicionalmente bizantino de aútó $\tau \eta \varsigma$, es decir, de testigo ocular, como se verá más adelante.

Pero no cabe duda de que, a finales del siglo XVII, el Mźras $\Sigma \varkappa \varepsilon v o \varphi u ́ \lambda a \xi$ sigue siendo tradicionalmente responsable de los objetos necesarios para la celebración de la liturgia ${ }^{58}$, y también de la colecta de las recetas pertenecientes al

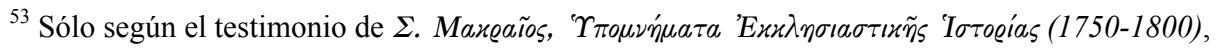

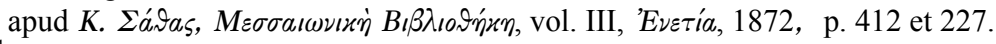


op. cit., p. ı'.

55 Sólo según el testimonio de Hammer, ibid. p. aı' y J. von Hammer, Histoire de l'Empire Ottoman, Paris, 1835-1843, libro XVI, p. 39.

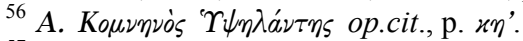

${ }^{57}$ Ibid., p. 684 y N. Iorga, op. cit., Paris, 1992, p. 246.

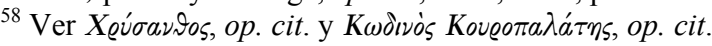


clero, que distribuye en su momento. En principio también es responsable de la Tesoro patriarcal.

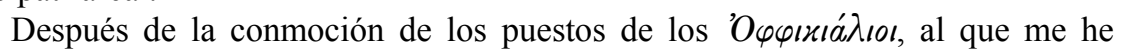
referido ya, el puesto de Gran skeuophylax es el que mejor se mantiene, no sólo ante la pérdida de importancia de los puestos originales, sino también contra la promoción de nuevas dignidades, inicialmente menos importantes.

Lo que se lee en los Asuntos eclesiásticos y políticos no parece corresponder al cargo de Gran Skeuphylax tradicional. Corresponde mejor el puesto de Gran ecónomo que, según Crisanto, patriarca de Jerusalén, verifica tanto los ingresos como el monto de cada transacción material, cuyo informe entrega al patriarca con regularidad ${ }^{59}$.

Actualmente, me es difícil comprobar si el Gran skeuophylax gozaba de ciertas

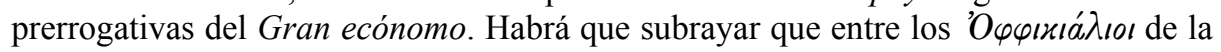
primera clase, la mayoría había llegado a ser dignidades sin sentido alguno, en el transcurso del siglo XVIII. En este sentido, se puede imaginar un reagrupamiento de las funciones bajo la batuta del dignatario que mejor se mantuvo en la jerarquía.

En todo caso, no cabe duda de que Athanásios Ipsilántis haya tenido un conocimiento muy preciso de toda suma de dinero que los civiles y el clero debían a la Gran Iglesia, y de toda suma de entrada y de salida en las cajas de la Iglesia. Las deudas que se tenían con la Iglesia, es decir, las que llevaban el sello de la corte patriarcal, son su primera preocupación y verifica, con celo metódico, las cantidades de dinero que entregan los candidatos para los puestos eclesiásticos.

Por otro lado, según versa el final de la obra, parece evidente, que tiene una función específica que lo pone en contacto permanente con el patriarca, ante el órgano


muy probablemente el comité instaurado por el patriarca Cirilo V, durante su segundo mandato, en $1752^{60}$, durante la reforma del Sínodo. La función de este órgano, que admite representantes de corporaciones laicas de Estambul, es la de regular el tesoro de la Gran Iglesia ${ }^{61}$.

\section{b- La cuestión de los «clanes» fanariotas}

El texto muestra que, a pesar de su espíritu independiente que reivindica, Athanásios Ipsilántis no está exento de la problemática de los clanes internos a los fanariotas en la época. Se sitúa, indudablemente, en el clan de la familia que lleva su nombre, aunque no se disponga de ninguna prueba material que lo haga primo del voivoda Aléxandros Ipsilántis, como lo afirma de forma muy verosímil E. RízosRankavís $^{62}$.

${ }^{59}$ X Qúravios, op. cit., p. 6.

${ }^{60}$ T. H. Papadopoullos, op.cit., p. 52.

${ }^{61}$ Para una definición de los Korvá, organizaciones comunales laicas temporalmente reconocidas por el gobierno otomano, cfr. G. Veinstein, op. cit. p. 331.

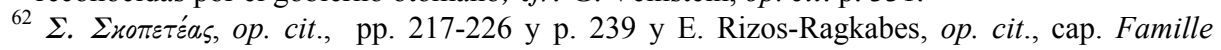
Ypsilanti. 


\section{Xavier. Agati: La romanidad oriental moderna: un testimonio sobre el papel...}

El clan de los malvados es el de los Mavrogénis. Uno de los objetivos indiscutibles del final de la obra es el de dar nuevo brillo al blasón de la familia Ipsilántis (de la que algunos de los más insignes miembros son acusados de alta traición con beneficio del Estado habsburgo), quitándoselo al de los Mavrogénis.

\section{3) Rasgos bizantinos de la obra, y su interés}

Los Asuntos eclesiásticos y políticos respetan en varios sentidos el esquema tradicional de la historiografía bizantina:

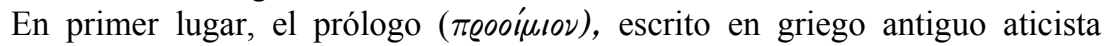
complejo (rasgo bizantino) atestigua la voluntad pensada, teorizada y viva de referirse a la tradición bizantina.

Pero, sobre todo, la conformación o fisionomía de la obra es típicamente bizantina: la mayor parte de la obra, a excepción del final, (que es un relato de eventos vividos por el autor), es una compilación histórica, rasgo mayor de la historiografía bizantina, y de la producción literaria bizantina en general. Siempre siguiendo el modelo bizantino, esta compilación se alarga cada vez más y hasta se disloca a medida que nos acercamos al final de la obra, con elementos de la vivencia propia del autor, expresamente orientados desde su punto de vista y opiniones.

Esta estructuración posee un rasgo distintivo de la literatura historiográfica


Miguel Pselo ${ }^{63}$, por ejemplo, defiende a principios del siglo XI este esquema, y define las virtudes históricas de la noción de avंoభía, el hecho de haber visto personalmente algunos sucesos, y de ponerse en escena a sí mismo.

Este esquema contribuye a atestiguar claramente una perennidad de la cultura bizantina, tres siglos después de la conquista de Constantinopla.

Cabe señalar que este texto de Ipsilántis se considera de diversas formas por los investigadores que lo han leído, pero constituye, sin duda, un texto de gran interés.

Las opiniones negativas se refieren sobre todo a la lengua (que se considera demasiado clacicista y muy henchida de turco y de rumano), al estilo seco y tajante, y sobre todo a la violencia de su parcialidad ${ }^{64}$.

Sin embargo, también se evoca el valor esencial de este testimonio histórico ${ }^{65}$. Es interesante porque el autor en sí está asociado con el poder otomano, con el poder religioso y con el poder político. Más allá de sus posiciones personales, podemos ver bosquejarse una imagen precisa de los lazos que unen a los dignatarios rûm entre

${ }^{63}$ E. Renauld (ed.), Psellos, Chronographie, Paris, 1926-1928 y J. Signes Cordoñer, Miguel Pselo, Emperadores de Bizancio, Madrid, Gredos, 2006.

${ }^{64}$ Para una opinión globalmente negativa, cfr. N. Iorga, Byzance après Byzance, Paris, 1992, pp. 244-247. Para la ausencia de objetividad, ver sobre todo E. Legrand, Eléments biographiques sur Athanase Comnène Ypsilantis, in Ephémérides Daces, tome II, Paris,

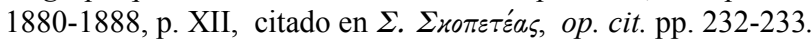

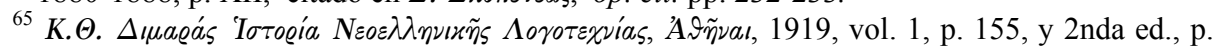
161. 
ellos, y a los dignatarios rûm con los dignatarios musulmanes, como se ve también bosquejarse la situación de los rûm en Estambul. La obra es en sí un testimonio del tema que trata: materia imperial, lengua imperial, autor de envergadura imperial.

K. G. Patrinélis ${ }^{66}$ llega a afirmar que Los asuntos eclesiásticos y políticos constituyen la historia más rica en informaciones que existe sobre la historia del helenismo del siglo XVIII: sobre la situación de la Gran Iglesia y sobre el patriarcado en sus relaciones con el gobierno otomano, sobre la economía de la Gran Iglesia, sobre las clases de los voivodas de Moldavia y Valaquia, y sobre el Imperio otomano en sí.

\section{4) Las temáticas esenciales del final del capítulo 6 del libro $X$}

El final del capítulo 6 del libro $X$ relata los tres primeros años de guerra entre el Imperio otomano y la coalición de Rusia y el Estado Habsburgo del Santo Imperio (la 2da guerra ruso-turca).

Los dos fragmentos elegidos para este estudio atañen particularmente la segunda mitad de 1788 hasta el mes de abril de $1789^{67}$.

El interés y la particularidad de este final de capítulo es que no se refiere casi en absoluto a la guerra en sí (es decir, a las operaciones militares que se desarrollan en Moldavia en ese momento, invadida por las tropas de los habsburgos y de los rusos, ni a la batalla naval que opone la flota otomana a la rusa en el Mar Negro), sino a sus consecuencias directas en Estambul, especialmente a las relaciones entre los dignatarios fanariotas y los dignatarios musulmanes a la cabeza del Estado.

Para ciertos fanariotas particularmente poderosos, la guerra va a convertirse en un nuevo medio de reforzar su influencia ante los dignatarios musulmanes más importantes del Imperio otomano.

En definitiva, todo el final de la obra gira en torno a un sólo tema: los fanariotas aliados a los hombres de Estado musulmanes no vacilan en perjudicar los intereses de su propia Nación y, particularmente los intereses de la Gran Iglesia, para


es el autor, lo observa todo.

Asistimos a un perpetuo vaivén entre dignatarios rûm y dignatarios musulmanes que define todo el final de esta obra cuyo escenario es Estambul, al mismo tiempo cerca y lejos de la guerra. Todos los dignatarios son de primer plano: para los rûm, se trata de puestos clave que ocupan los fanariotas ya mencionados, a los que se suman los miembros del Sínodo y el patriarca. Para los musulmanes, se trata del reemplazante del Gran visir, estando éste en el frente, interviniendo a través de cartas o emisarios, del Kaptan-ı deryâ (Ministro de la Marina), del Re'îs ül küttap (Secretario de Estado o Canciller del Imperio), del Baş defterdâr (Ministro de finanzas), del Bostancı başı (Jefe de la policía), del Hâzinedâr başı (Jefe del Tesoro Nacional), del Tersâne emîni (Jefe del arsenal), del Darpâne emîni (Jefe del Palacio

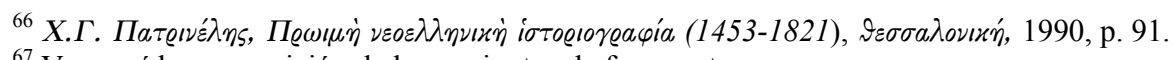

${ }^{67}$ Ver aquí la composición de los conjuntos de fragmentos. 


\section{Xavier. Agati: La romanidad oriental moderna: un testimonio sobre el papel...}

de la moneda) y del Kahyâ bey (suerte de Ministro del interior, teniente de los jenízaros); y además, intervienen los dos Pâdişâh de la época: Sultân 'Abd ül Hamîd I al final de su reinado, y Sultân Selîm III, entronizado el 27 de marzo de 1789.

Todo el final de la obra denuncia continuamente un tándem político, una verdadera diarquía nociva para los intereses de la Gran Iglesia y de los rûm, compuesta del Gran visir, Koca Yusuf Paşa, y del miembro más insigne del clan rûm de los Mavrogénis, el voivoda de Valaquia Nikólaos Mavrogénis. Según el autor, este voivoda controla al patriarca y al Sínodo, y a otros dignatarios musulmanes, como el Baş defterdâr (Ministro de finanzas) por ejemplo, blandiendo la amenaza de destitución pronunciada por el Gran visir bajo sus propias órdenes.

\section{IV- La destitución del patriarca ecuménico de Constantinopla Procopio Pelekásis $^{68}$}

El exilio del Patriarca, personalidad que concentra oficialmente la mayor parte de la legitimidad bizantina, ocupa en la obra un lugar particular, pues constituye el punto culminante. El final de la obra es un fin pensado, no está hecho a la ligera; la salida de Procopio significa probablemente mucho más de lo que parece para el autor: la despedida de sus propias funciones eclesiásticas y civiles, de toda su inmensa actividad literaria y de su propia vida, pues sabemos que murió poco después. De hecho, se tiene la impresión de una suerte de duo formado con él y el patriarca de Constantinopla, que cimienta su fidelidad para con la Iglesia, y de un hastío final de las desgracias de la Iglesia y de las de la vida.

El autor presenta la destitución del patriarca de Constantinopla como una consecuencia ineluctable, resultado complejo de varios factores conjugados. Con esta destitución caemos en cuenta del poder y la posición del patriarca en ese momento.

Según el autor, el mayor perjuicio del patriarca, que frecuenta a diario, es el estar sometido a la voluntad del joven Intérprete del mar, que luego se hace Logoteta de la Gran Iglesia, Stéfanos Mavrogénis, y, en este sentido, no oponerse a su tío tirano: Nikólaos Mavrogénis, culpable de todos los perjuicios. Que el patriarca no se oponga a ambos Mavrogénis tiene consecuencias de mucho peso: éstos se empeñan en acomodar a los pretendientes de su elección en las sedes de las metrópolis, y así enriquecerse percibiendo liberalidades de uso, y Nikólaos Mavrogénis se libra a exacciones en su propio territorio para poder pagar al Gran visir y así recomendarse ante él.

Sin embargo, a pesar de esta crítica, se percibe la simpatía del autor con el patriarca.

\footnotetext{
${ }^{68}$ De este primer conjunto de doce fragmentos de la obra: tres fragmentos se concentran en el orden de venta de plata al Palacio de la moneda (pp. 702-704, 706-707, 711-712); cuatro fragmentos se concentran en la mobilización de los marineros rûm (pp. 683, 686, 707-709, 712), y cinco fragmentos narran los sucesos puntuales determinantes para la destitución del patriarca (pp. 681-682, 693, 698-703, 712-713).
} 
Un comité compuesto por eclesiásticos y civiles rûm piden la destitución a través de un documento llamado ' $a r z-u$ hâl (petición oficial), entregado por una serie de intermediarios al Pâdişâh Sultân Selîm III. Este acepta la destitución y se la hace efectiva el 30 de abril de 1789, con el exilio del patriarca a Lesbos.

Las explicaciones relacionadas a los acontecimientos que da el autor sobre esta desgracia son las siguientes: el patriarca había sido víctima de dos sucesos relacionados con la coyuntura de guerra, y de una serie de sucesos más puntuales, pero también determinantes. Sin embargo, la razón de fondo es la posición incómoda del patriarca, entre los rûm, los dos dignatarios rûm tan influyentes, y los miembros musulmanes del gobierno otomano.

\section{1) La movilización mal administrada de los marineros rûm}

El Kaptan-ı deryâ (Ministro de la marina) ordena en 1788 y 1789, en varios territorios del Imperio, la movilización de marineros rûm para la batalla naval en el mar Negro: todas las aldeas que sirven al Imperio deben pagar cierta suma de dinero para el sustento de estos marineros (lo que significa pagar una parte de su propio servicio de armas).

El autor lo considera ilegal, pues constituye un impuesto suplementario que el Corán no prevee.

Como jefe civil de los rûm, el patriarca se encarga de reunir a los hombres en el tiempo concedido, pero no lo logra debido a las dificultades económicas de las aldeas. Esta derrota acarrea la destitución del Kaptan-ı deryâ, y el descrédito del patriarca ante los suyos.

\section{2) Medida discriminatoria de orden de venta de plata al Palacio de la Moneda}

Entre 1788 y 1789, el Patriarca recibe la orden de reunir en su nación y enviar al Palacio de la moneda cierta cantidad de plata, y hasta de oro, destinada a acuñar una nueva moneda para hacer frente a la crisis monetaria que atravesaba el Imperio.

El autor, por su parte, considera que esta cantidad está sobre-evaluada en relación con las posibilidades reales de la nación rûm, si se la compara con las cantidades que se piden al Haham başı (patriarca de los judíos) y al patriarca armenio.

El Palacio de la Moneda compra este metal, sin que se trate de un impuesto suplementario; pero como la plata no se paga sino una vez acuñada la moneda, la medida parece ser un impuesto extraordinario.

Para cumplir con el volumen de metal requerido, el Patriarca se ve obligado, en varias ocasiones, a ejercer presión sobre los rûm, sobre todo sobre las corporaciones que se quejan abiertamente de él. Por otra parte, el Re'îs ül küttap (Secretario de Estado o Canciller del Imperio) amenaza al patriarca de muerte si no llegara a reunir la cantidad de metal requerida. 


\section{Xavier. Agati: La romanidad oriental moderna: un testimonio sobre el papel...}

\section{3) Sucesos puntuales determinantes}

El Patriarca se convierte en el blanco de varias acusaciones redactadas oficialmente por ciertos rûm que alegan avaricia personal estafa, o traición al servicio de los rusos. Una vez confundidos, dos de los autores de estas acusaciones, miembros del bajo clero, recelan el derecho de castigo del que goza el patriarca y que por lo tanto se encontraba aun en vigor ${ }^{69}$ : uno es exiliado al monte Atos y el otro se convierte al Islam para escapar al látigo y a la tortura que le impondría el patriarca.

El hecho de mayor incidencia es la sucesión al trono del patriarca de Alejandría del 12 de septiembre de 1789. El patriarca logra que el Sínodo elija a su propio cliente pero, el mismo día, el Darpâne emini (Jefe del Palacio de la moneda) obtiene la nominación efectiva al trono del patriarca de Alejandría de otro jerarca, cliente suyo. El patriarca de Alejandría permanece en su lugar, pero el Re'îs ül küttap por el que pasa el asunto, se exaspera con el patriarca Procopio porque hubiera recibido dinero si el cliente del Darpâne Emini hubiera accedido al puesto.

Luego, debido a las quejas de un fanariota a quien su deudor eclesiástico no había pagado, el Re'îs ül küttab amenaza con la pena capital al patriarca (a quien se había amenazado ya por el asunto de la plata).

De esta manera, el dicho grupo se reune, da un 'arz-u hâl al Pâdişâh Sultân Selîm III a través de un intermediario donde piden la elección de otro patriarca, y Procopio es destituído.

\section{4) Análisis}

¿En qué medida el proceso de destitución contraviene al uso establecido según el cual sólo el Sínodo tenía el derecho de acusar al patriarca ante el Pâdişâh, que estaba limitado a su vez por el Divân? Se desconoce la composición exacta del comité responsable de la destitución: ¿se trata de representantes eclesiásticos del Sínodo y de

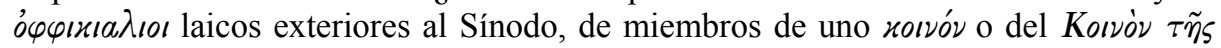

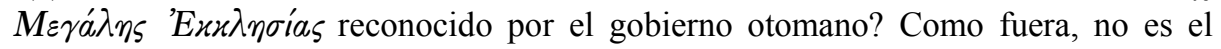
Sínodo como tal quien actúa, tampoco se hace referencia a una reunión del Divân: la destitución parece no ser conforme al proceso establecido después de la Conquista.

En cuanto a las demás acusaciones contra el patriarca, tres de las cuatro (de las que dos provienen del bajo clero) llegan casi directamente a las manos del Pâdişâh . Éste da la impresión de que el menor rûm puede acusar al patriarca ante el Pâdişâh, lo que limita aun más la inmutabilidad en cuestión del patriarca.

Finalmente, los fragmentos son explícitos sobre la sumisión de las nominaciones eclesiásticas a la voluntad de los fanariotas influyentes pero también a la de los dignatarios musulmanes, un hecho poco estudiado en detalle.

${ }^{69}$ T. H. Papadopoullos, op.cit., p. 34. 
Byzantion Nea Hellás 28, 2009: 127-164

\section{V- La acusación por alta traición del voivoda de Moldavia Aléxandros Ipsilántis $^{70}$}

El final de la obra de Ipsilántis narra continuamente la desgracia del voivoda de Moldavia Aléxandros Ipsilántis, familiar del autor. Esta desgracia se pronuncia con la alta traición de la que saca provecho el Estado habsburgo, enemigo público, ante la acusación del voivoda de Valaquia, Nikólaos Mavrogénis, el 7 de mayo de 1788.

Justificada o no, este tipo de acusación inquiere la orientación política de la identidad de las élites rûm del Imperio otomano: fieles al Imperio o, al contrario, dispuestos a desprenderse de él, utilizando las veleidades expansionistas (con coloración panortodoxa) de Rusia, apoyados por su aliado, el Imperio habsburgo.

La armada de los habsburgos captura al voivoda mientras asumía la dirección de las tropas otomanas en Moldavia, cuando los austriacos invaden la capital Yaşi en abril de 1788, y lo encarcelan en Brno.

Athanásios Ipsilántis declara que Nikólaos Mavrogénis hace una acusación falsa y se opone a ciertas fuentes que sugieren que Ipsilántis buscaba realmente una alianza con el Estado habsburgo, y hasta un plan de secesión.

La difamación por alta traición no es ninguna novedad entre los dignatarios fanariotas ${ }^{71}$. Esta calumnia les permite presentarse como defensor del Imperio ante los dirigentes musulmanes, vencer a un rival, favorizando el acceso a otro voivoda que pertenezca a su propio clan, o favorizar hasta su propio acceso y, finalmente, sacar beneficio de que el tesorero del Estado recupere el dinero de la venta de todos los bienes del traidor o el premio por su liberación de la prisión.

El autor da a entender que para llevar a cabo esta calumnia, el voivoda de Valaquia y el Gran visir habían hecho un común acuerdo de antemano ${ }^{72}$.

La acusación no es tan sólo contra el voivoda ausente de Estambul, sino además contra miembros de su familia que residen en Estambul: contra su hijo Konstantínos Ipsilántis y el esposo de su hija, Aléxandros Mános, que se destaca por su puesto-clave de Gran logoteta de la Gran Iglesia, al que me he referido ya.

Esta vez, la ventaja de acusar de traición a un Gran logoteta es permitir a otros rûm pretender al puesto, una vez que éste vacante. En realidad, el autor no da la responsabilidad de este cálculo al voivoda de Valaquia, el mismísimo Mavrogénis, sino al sobrino de éste, Stéfanos Mavrogénis, entonces Intérprete del mar, y al patriarca. Es muy probable que ambos dignatarios concertaran de antemano y que el patriarca acusara Aléxandros Mános a propósito, cuando éste no había sido nombrado

\footnotetext{
${ }^{70}$ Este segundo conjunto contiene cinco fragmentos de la obra: pp. 687-691, 692, 694, 696-697, 698-698.

${ }^{71}$ Para las ventajas que sacan los fanariotas de la práctica de la difamación por alta traición como por la técnica de la carta codificada que advertía al futuro acusado, ver M.-P. Zallony, Essai sur les Phanariotes, Marseille, 1824, pp. 124-125.

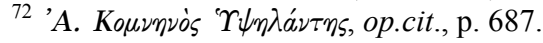




\section{Xavier. Agati: La romanidad oriental moderna: un testimonio sobre el papel...}

en las acusaciones del voivoda de Valaquia. El autor llega a mencionar una «entrevista misteriosa» en la que el patriarca habría revelado su intención de acusar al Gran logoteta con quien había tenido antiguamente alguna diferencia personal ${ }^{73}$.

Ambos miembros del clan Ipsilántis, el hijo del voivoda y el Gran logoteta, son juzgados cómplices y encarcelados en la prisión llamada Horno del Bostancı başı, prisión destinada a los hombres de Estado y a los favoritos en desgracia.

Este encarcelamiento trae consigo dos consecuencias esenciales.

\section{1) La injerencia renovada de los hombres de Estado musulmanes}

El tema de la ingerencia de los hombres de Estado musulmanes en la nominación de los dignatarios eclesiásticos está bastante representada en la obra de Ipsilántis y constituye, en él como en otros autores, una suerte de topos.

La particularidad de la situación es que se trata del poder de un puesto ocupado por un viviente, y que las leyes de la Iglesia lo prohiben explícitamente, a menos que el que lo ocupaba anteriormente desistiera o fuera culpable de heresía. De hecho, la acusación de traición política no es un motivo de suspensión de cargo, pero lo que es realmente sorprendente es que, entre los miembros del Sínodo, la renuncia de Aléxandros Mános haya sido aceptada, aunque con disgusto ${ }^{74}$.

Se desencadena una lucha entre varios dignatarios rûm que se libran a una serie de maniobras para obtener el cargo de Gran logoteta gracias a la mediación de un dignatario musulmán.

Me es imposible aquí entrar en los detalles de estas maniobras, que dan lugar a situaciones casi absurdas: nuevos candidatos rûm no vacilan en pagar una nueva suma de dinero para ser nombrados a pesar de que el título de nominación del firmán hubiese sido atribuido ya. Cuatro candidaturas llegan a superponerse, tres reciben el concierto del Pâdişâh Sultân 'Abd ül Hamîd I (que se retracta un par de veces en su decisión), y una el concierto del Gran visir que usurpa las tres decisiones precedentes del Pâdişâh.

El tercer candidato se lleva el puesto, Stéfanos Mavrogénis, el más rico, apoyado por los dignatarios musulmanes, por el Sínodo y por el patriarca: todos temen la destitución pronunciada por su tío.

Lo realmente interesante es la naturaleza de los cruces entre los candidatos rûm, el Sínodo, y el patriarca, por un lado, y los diferentes dignatarios musulmanes por el otro, para favorizar o impedir una nominación, cruces con sus propias reglas que merecen un estudio profundizado.

\footnotetext{
${ }^{73}$ Ibid. p. 687.

${ }^{74}$ En el fragmento en cuestión (p. 689), la esposa del Gran logoteta encarcelado, la Domniță (hija del voivoda de Moldavia, acusado de traición) presenta al Sínodo una carta que equivale a una renunciación de su esposo. Los miembros del Sínodo no desean considerar dicha carta, lo que equivale a dar la razón al calumniador.
} 
Puedo dar tan sólo perspectivas de la complejidad de todos estos vaivenes; sin embargo, estas maniobras muestran la realidad del poder de los dignatarios rûm en ese momento de la historia del Imperio otomano.

Fuera del pago al Pâdişâh o al Gran visir del que se ha hablado, un candidato rûm (que busca su nominación definitiva) debe hacer que el patriarca busque (sin previa orden del gobierno otomano) los precedentes firmanes de nominación de los antiguos poseedores del título, para volver a escribirlos a su nombre.

El Sínodo, por su lado, puede hacer uso del derecho a respuesta o de protesta

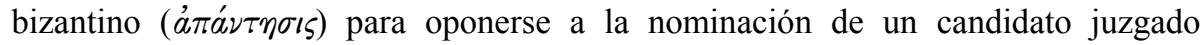
indeseable, pero no hace uso de este derecho para protestar contra la injerencia del poder otomano en las nominaciones eclesiásticas: alega sólo el pretexto que el candidato nombrado es demasiado joven para el cargo, lo que quiere decir que no denuncia el principio de injerencia, y que participa de forma activa en las maniobras. El Patriarca puede escribir un 'arz (comunicación) para apoyar a un candidato, su cliente, a pesar de las dos nominaciones ya efectuadas.

Los dignatarios musulmanes, por su parte, sin mencionar al Pâdişâh y al Gran visir, que parecen jugar voluntariamente con las diferentes candidaturas y aceptar la del que ofrezca más, pueden hacer uso de la presión. Por ejemplo, el Pâdişâh o el Gran visir pueden enviar al Re'is ül küttap y al Kahyâ bey para desalentar a un candidato y pedirle un pago de dinero suplementario. Un dignatario particular también puede apoyar una candidatura mediante una carta al Gran visir.

\section{Sínodo}

\section{2) La constitución excepcional de una doble garantía que presiona al}

Para evitar la ejecución de los dignatarios acusados de alta traición, y la confiscación de sus bienes, existe un proceso: liberar a estos dignatarios a cambio de una multa, cuyo nombre otomano es «precio por no ser ejecutado» (katlâ bedel).

En el caso de los dos miembros del clan Ipsilántis prisioneros en Estambul, el Gran visir opta por esta solución por temor, según el autor, de la presión de los poderes europeos que se enterarían, a través de la venta pública de los bienes, que el voivoda de Moldavia había sido acusado injustamente; por otro lado, en este período de guerra ningún comprador lo suficientemente afortunado se presentaría para adquirir los bienes y, además, la avaricia personal del Gran visir le hace esperar obtener para sí una parte del pago.

Para asegurarse de que el monto sería entregado, era necesaria la garantía de otra persona. Ésta podía ser de dos tipos: la garantía llamada "de la persona" del detenido, en el vocabulario jurídico otomano; es decir, que debía asegurar que el detenido, una vez liberado, no se fugaría al extranjero sin pagar la multa. La otra garantía, la financiera, comprometía al signatario a pagar la suma si el detenido liberado no la pagaba. 


\section{Xavier. Agati: La romanidad oriental moderna: un testimonio sobre el papel...}

Aquí, la garantía se impone al Sínodo por primera vez desde la Conquista. En consecuencia, los miembros del Sínodo la rechazan, considerando que constituiría un precedente grave ${ }^{75}$.

Debido a los juegos de influencia entre los diferentes dignatarios, se llega a una situación inédita: se constituyen dos garantías, una "de la persona" de los detenidos, y otra financiera. Como la primera es indirecta, el Sínodo acepta presentarse como garante de cuatro garantes laicos (entre los cuales se encuentra el autor), que eran, a su vez, garantes de la persona de los detenidos.

\section{3) Análisis}

Con la lectura de estos fragmentos se constata, primeramente, que más que procesos fijos y respetados, se trata de circunstancias, de pragmatismo y de interés, vectores de los movimientos de nominación en la Gran Iglesia.

Por otra parte, para el autor, se trata de mostrar que el voivoda acusado es, en realidad, inocente, lo que es evidentemente prioritario para presentar a la familia Ipsilántis desde un ángulo positivo.

Más allá de la denuncia de las prácticas que debilitan el poder de la Iglesia, nos encontramos en una lógica que valora el entendimiento entre los dignatarios rûm y los musulmanes del Imperio otomano, y que respeta el fundamento del poder de la Gran Iglesia garantizado por el Imperio, a pesar de las dislocaciones que sufre.

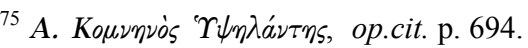




\section{Conclusión general de este estudio}

Las convicciones del autor son claras: para él, el patriarca de Constantinopla es fiel al Imperio otomano pero está sumido a los fanariotas, y el voivoda Aléxandros Ipsilántis es acusado injustamente de traición por otro fanariota. Athanásios Ipsilántis defiende la fidelidad al Imperio otomano como una elección cristiana histórica que remonta a 1453, pero, al mismo tiempo, critica con severidad a los dignatarios sin escrúpulos del Imperio, sean éstos fanariotas o musulmanes.

Según el autor, la Iglesia sigue siendo la garantía de toda la continuidad romana, ya sea religiosa, política o solamente cultural.

Los dos grupos de fragmentos estudiados otorgan precisiones importantes sobre lo que se conoce sobre la situación de los rûm a finales del siglo XVIII, y permite afinar nuestro juicio sobre el tema de la continuidad bizantina asumida por los rûm del Imperio otomano.

Cultural, lingüística y literariamente, la continuidad es indiscutible, como se ha podido constatar. En el plano religioso y político, la situación es compleja.

En el plano religioso, el texto de Ipsilántis ilustra perfectamente la idea de una decadencia de la posición del Patriarca en relación al modelo defendido por el propio Imperio otomano: el pragmatismo del Imperio hizo variar los acuerdos iniciales, y los propios cristianos, en el período de los fanariotas, tienen un papel esencial en esta decadencia. Sin embargo, el texto confirma, implícita pero constantemente, este rasgo notable de bizantinismo religioso que es el imperialismo religioso del Patriarcado de Constantinopla sobre todos los pueblos cristianos calcedonios (particularmente los moldavos y los valacos), que perduró porque servía a los intereses otomanos.

En el plano político, no es fácil hablar de continuidad bizantina. En la forma de gobernar la Moldavia y la Valaquia de los fanariotas, los estudios que se han consultado han identificado varios rasgos de bizantinismo, como se ha visto, por lo menos en lo relativo a la cultura política y a la legislación, así como en la tendencia autocrática de los voivodas... y se ve, por lo menos en el texto que nos concierne, un autocratismo de Nikólaos Mavrogénis.

Este estado de hecho parece haber sido tolerado o alentado por el gobierno otomano en la medida que favoreció la cohesión de los rûm y, por lo tanto, los intereses del Imperio.

Además, el hecho de que el gobierno otomano acomodara a fanariotas en los tronos moldavos y valacos demuestra la idea de un partenariado entre la élite fanariota y la élite musulmana del Imperio.

Sin embargo, como quiera que sea, la tradición política bizantina, al menos en lo que respecta su carácter imperialista y autocrático fracasó debido a la revolución de las ideas que abrazaba a toda Europa en la época. La revolución intelectual de las Luces y los movimientos nacionalistas del siglo XIX, utilizados por los estados de Europa occidental, llegaron a producir la implosión del Imperio otomano, en lo que llamamos el Asunto de Oriente, y el fracaso de la idea de algún renacimiento de 
Xavier. Agati: La romanidad oriental moderna: un testimonio sobre el papel...

Bizancio. Las Luces y el romanticismo político dieron nacimiento a modelos políticos alejados del de Bizancio. Si se añade a todo esto el expansionismo europeo, se puede coincidir con N. Iorga, según quien, el Imperio otomano y la tradición bizantina vivieron y murieron siguiendo el mismo movimiento.

El texto estudiado muestra que, en definitiva, la cultura eclesiástica y política bizantina transmitida por la Gran Iglesia y adaptada al Imperio otomano, dan más bien una imagen de un sistema elaborado en el que las partes son integradas al conjunto, imagen de una sinergía en evolución en función de los intereses del momento, pero homogénea y que posee sus propias reglas.

He aquí la contribución de este texto a los estudios otomanos, a los estudios bizantinos, a los estudios religiosos y a los estudios clásicos en su conjunto. 
Byzantion Nea Hellás 28, 2009: 127-164



\section{El Pâdişâh 'Abd ül Hamîd I}

Colección de la Fundación Suna e İnan del Museo de Pera, Estambul Pintura de Jean-François Duchâteau (?)

Entre 1774-1789 
Xavier. Agati: La romanidad oriental moderna: un testimonio sobre el papel...

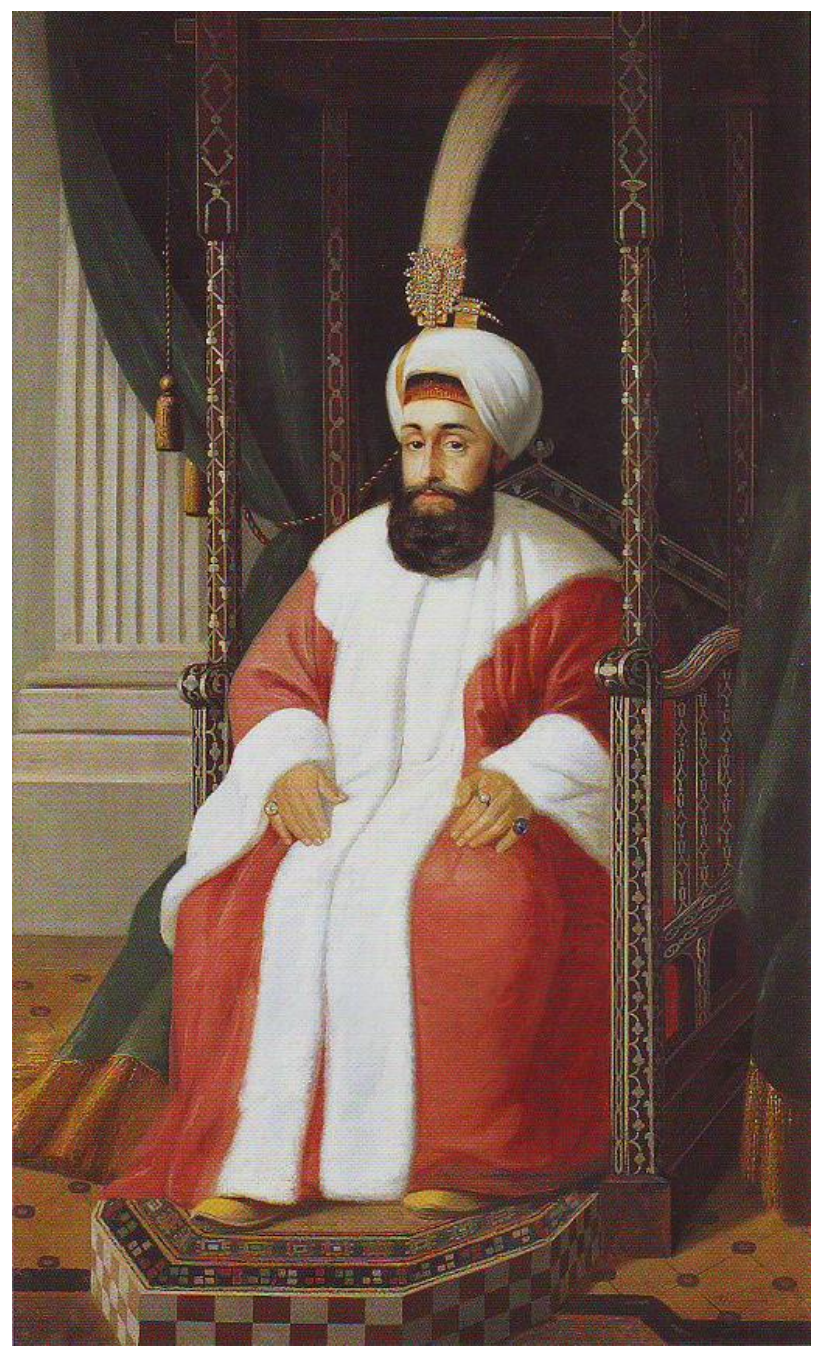

\section{El Pâdișâh Selîm III.}

Colección de la Fundación Suna e Inan del Museo de Pera, Estambul Pintura de Joseph Warnia-Zarzecki

Final del siglo XIX 
Byzantion Nea Hellás 28, 2009: 127-164

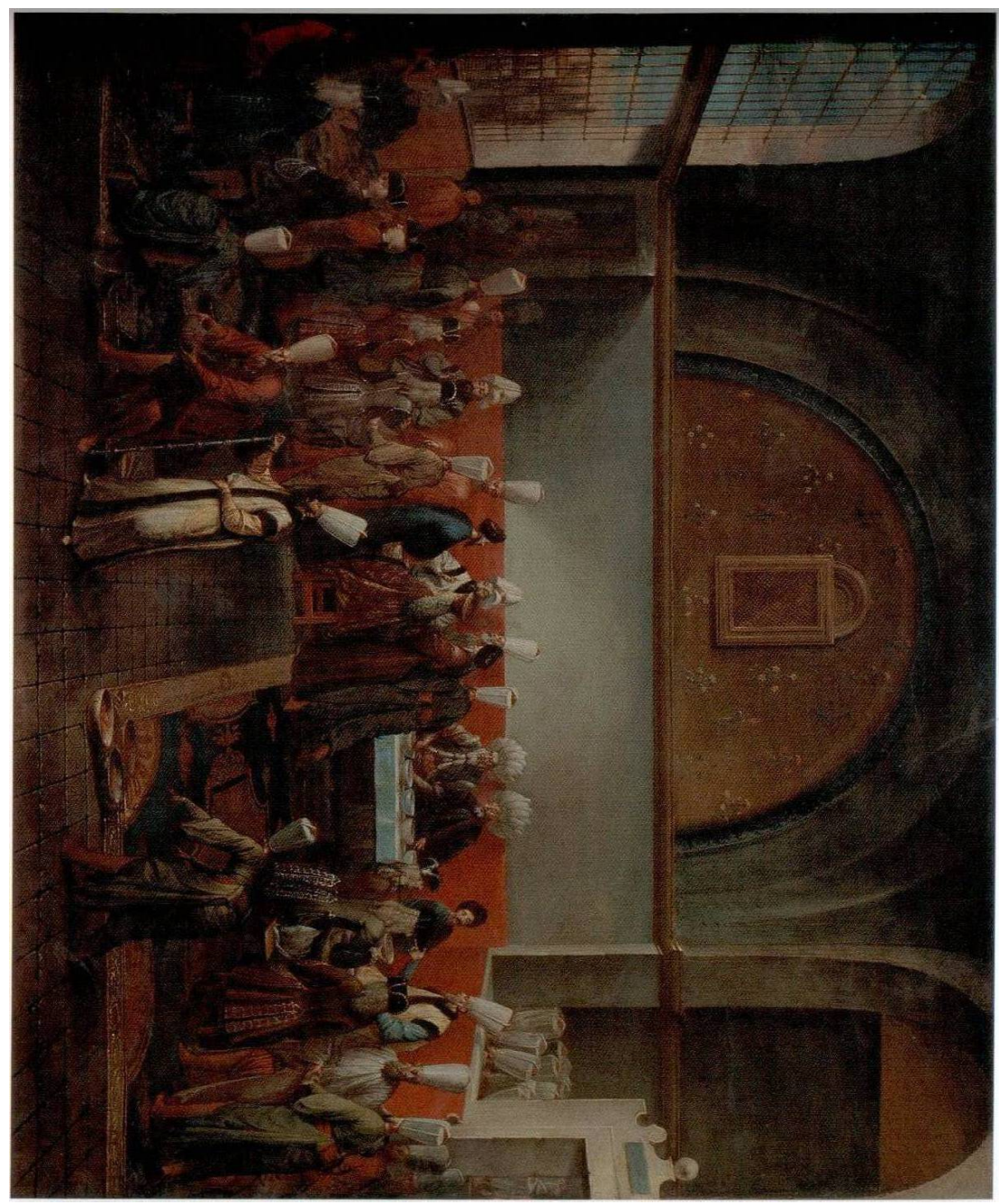

Pintura de Jean-Baptiste Vanmour, 1725 (?)

Colección de la Fundación Suna e Ínan del Museo de Pera, Estambul

Cena en la sala llamada Kubbe altı ("Debajo de la cúpula") del Palacio Imperial de Estambul, en honor a un Embajador europeo, antes de su recepción en la sala del trono ('Arz odasl). El Consejo Supremo o Divân Augusto (Divân-ı Hümâyûn) está presente. En el centro de la pintura se ve el Embajador de espaldas, entre dos intérpretes, muy probablemente rûm (o "romanos") fanariotas. Puede divisarse al Pâdişâh (el sultán) escondido detrás de la reja, observando la escena. 
Xavier. Agati: La romanidad oriental moderna: un testimonio sobre el papel...



Señoras rûm fanariotas

Colección de la Fundación Suna e Ínan del Museo de Pera, Estambul Daniel Valentine Rivière (?) 1840 
Byzantion Nea Hellás 28, 2009: 127-164

\section{Bibliografía}

\section{1) LIBROS Alfabeto griego}

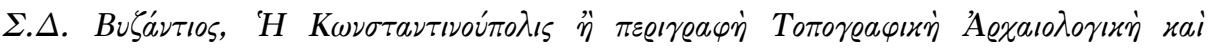

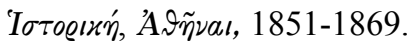

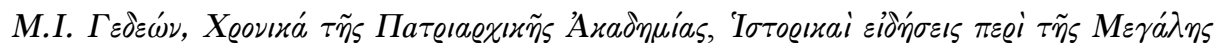



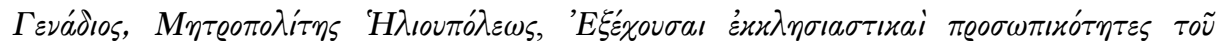



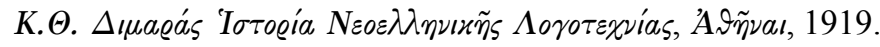

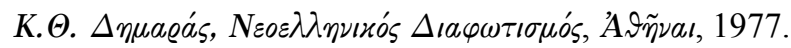

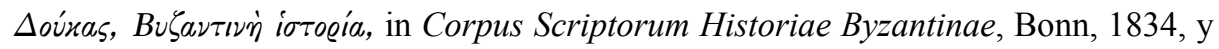
in Migne, Patrologia Graeca, tomo 157, Paris, 1866.

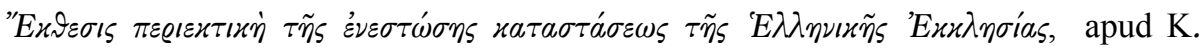



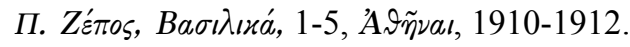

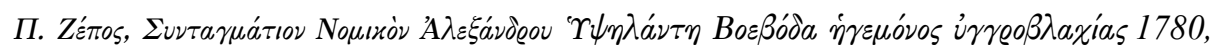

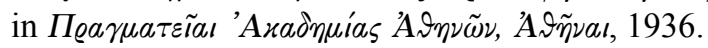

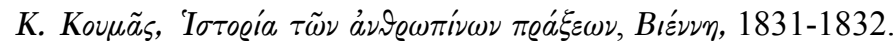



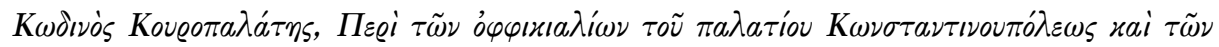

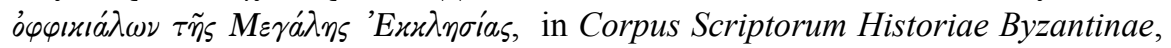
Bonn, 1839, y in Migne, Patrologia Graeca, vol. 157, Paris, 1866.

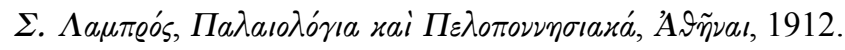

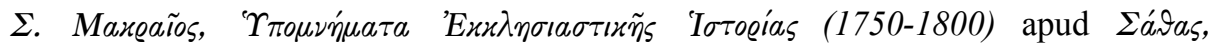

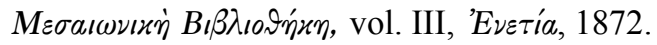




\section{Xavier. Agati: La romanidad oriental moderna: un testimonio sobre el papel...}

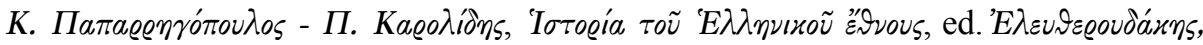
Aจ ที่al, 1925.



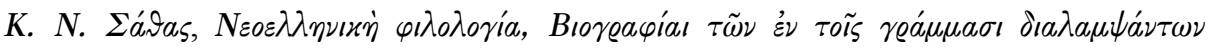

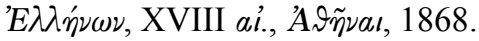

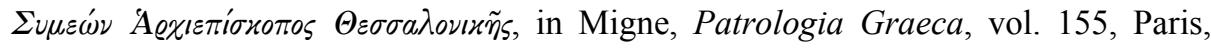
1866.

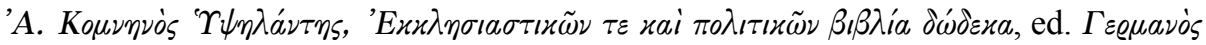

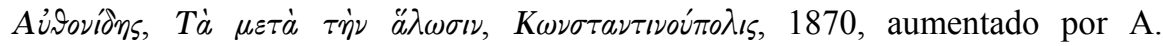
Papadópoulos-Keramévs, 1909.

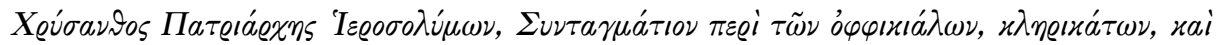

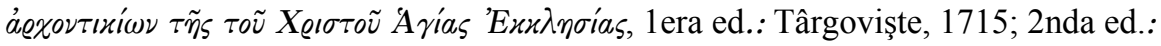
'Evยтía, 1778.

\section{Alfabeto latino}

Bibliographie hellénique ou description raisonnée des ouvrages publiés par les Grecs, XVIIIème siècle, 2 vol., ed. L. Petit, H. Pernot, Paris, 1894-1903.

D. Cantemir, The History of the Growth and Decay of the Ottoman Empire (traducido del latín por L. Tendal), London, 1756.

Documente privitoare la Istoria Românilor, culose de E. Hurmuzaki, ed. A. Papadópoulos-Kermanévs, Bucureşti, 1909.

D’Ohsson, Tableau général de l'Empire Ottoman (traducción en francés), Paris, 1824.

Encyclopédie de l'Islâm, Paris, 1975-2002 (última edición).

C. Erbiceanu, Cronicarii greci care au scris despre romani in epoca fanariota, Bucureşti, 1888.

G. Finlay, History of Greece, Oxford, 1877.

J. von Hammer, Histoire de l'Empire Ottoman, Paris, 1835-1843. 
Byzantion Nea Hellás 28, 2009: 127-164

N. Iorga, Byzance après Byzance, Paris, 1992.

N. Iorga, Geschichte des Osmanischen Reiches nach den Quellen dargestellt, Gotha, 1909-1912.

E. Legrand, Bibliothèque grecque vulgaire, Paris, 1880.

E. Legrand, Eléments biographiques sur Athanase Comnène Ypsilantis, in Ephémérides Daces, tome II, Paris, 1880-1888.

A. Mavrocordat, Despre originea Mavrocodaților, in Arhiva ştiințifice şi literare, Iaşi, 1894.

T. H. Papadopoullos, Studies and Documents relating to the History of the Greek Church and People under Turkish Domination, Biblioteca Graeca - Aevi Posteriores - I, Brussells, 1952.

L. Petit, X. Siderides, M. Jugie, Oeuvres complètes de Scholarios, 8 vol., Paris, 19281936.

E. Renauld (ed.), Psellos, Chronographie, Paris, 1926-1928.

J. Rizos-Neroulos, Cours de littérature grecque moderne, 2nda ed., Genève, 1828.

E. Rizos-Ragkabes, Le Livre d'or de la noblesse phanariote en Grèce, Roumanie, Russie, Turquie, par un Phanariote, Athènes, 1892.

J. Signes Cordoñer, Miguel Pselo, Emperadores de Bizancio, Madrid, Gredos, 2006.

G. Veinstein, Les provinces balkaniques (1606-1774), in Histoire de l'Empire Ottoman, sous la direction de R. Mantran, Paris, 1989.

M.-P. Zallony, Essai sur les Phanariotes, Marseille, 1824. 
Xavier. Agati: La romanidad oriental moderna: un testimonio sobre el papel...

\section{2) REVISTAS}

\section{Alfabeto griego}

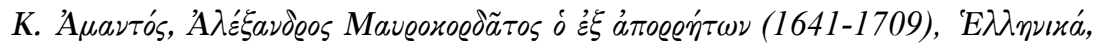
Aจ

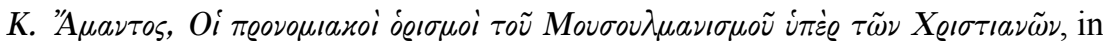

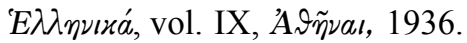

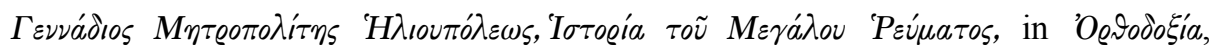

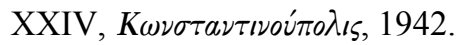

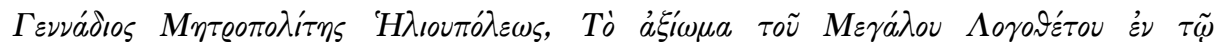

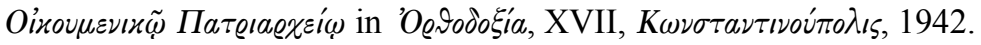

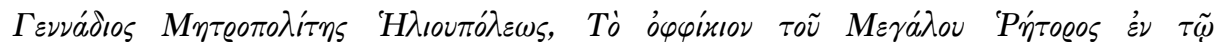



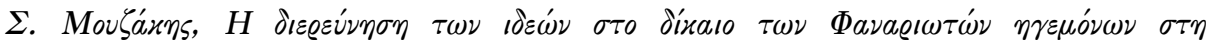

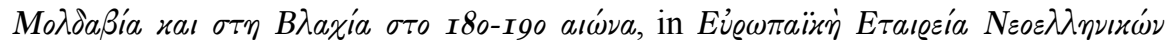

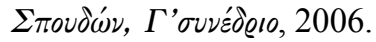

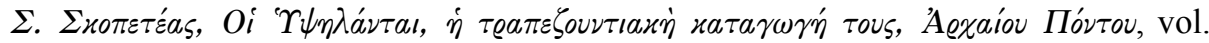

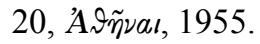

\section{Alfabeto latino}

V. Georgescu, The Political Ideology of the Rumanian Boyards in the XVIIIth Boulder, Colorado University, 1973.

N. Iorga, Sfîrşitul lui Alexandru Vodă Ipsilanti, in Revista istoricăa, XX, Bucureşti, 1934.

M. Richard, Répertoire des Bibliothèques et des Manuscrits grecs, Publications de l'Institut de Recherche et d'Histoire des Textes, no 1, Paris, 1948.

P. Zepos, La politique sociale des princes phanariotes, in Balkan Studies 11, Thessaloniki, 1970. 